OPEN ACCESS

Edited by:

Sarah M. Temkin,

Virginia Commonwealth University,

United States

Reviewed by:

Guenther Georg Steger,

Medizinische Universität Wien,

Austria

Dayanidhi Raman,

University of Toledo, United States

${ }^{*}$ Correspondence:

Alexey A. Larionov al720@medschl.cam.ac.uk, alexey_larionov@hotmail.com

Specialty section: This article was submitted to Women's Cancer,

a section of the journal

Frontiers in Oncology

Received: 30 August 2017

Accepted: 14 March 2018

Published: 03 April 2018

Citation:

Larionov AA (2018) Current Therapies for Human Epidermal Growth Factor Receptor 2-Positive Metastatic

Breast Cancer Patients.

Front. Oncol. 8:89.

doi: 10.3389/fonc.2018.00089

\section{Current Therapies for Human Epidermal Growth Factor Receptor 2-Positive Metastatic Breast Cancer Patients}

\author{
Alexey A. Larionov* \\ Department of Medical Genetics, School of Clinical Medicine, University of Cambridge, Cambridge, United Kingdom
}

The median survival of patients with human epidermal growth factor receptor 2 (HER2)positive metastatic breast cancer (MBC) has more than doubled, since the discovery of HER2-targeted treatments: it rose from less than 2 years in 2001 (prior introduction of trastuzumab) to more than 4 years in 2017. The initial generation of HER2-targeted therapies included trastuzumab with taxanes in the first line, followed by the addition of lapatinib and by a switch to another cytotoxic agent after progression. Results of CLEOPATRA, EMILIA, and TH3RESA trials have changed this clinical practice. The current consensus includes horizontal dual blockade (trastuzumab + pertuzumab) with taxanes or vinorelbine in the first line, followed by trastuzumab-emtansine (T-DM1) in the second line, with addition of lapatinib in the later lines of treatment. However, the fast and simultaneous development of new drugs led to a relative shortage of clinical evidence to support this sequence. Triple-positive breast cancers (TPBC), which express both hormonal receptors and HER2, constitute nearly half of HER2-positive cases. For these tumors, the current consensus is to add endocrine therapy after completion of cytotoxic treatment. Again, this consensus is not fully evidence-based. In view of the recent progress in treatment of estrogen-receptor positive breast cancers, a series of trials is evaluating addition of CDK4/6 inhibitors, aromatase inhibitors or fulvestrant to HER2-targeted and cytotoxic chemotherapy in TPBC patients. Despite the remarkable progress in treatment of HER2-positive breast cancer, metastatic disease is still incurable in the majority of patients. A wide range of novel therapies are under development to prevent and overcome resistance to current HER2-targeted agents. This review discusses pivotal clinical trials that have shaped current clinical practices, the current consensus recommendations, and the new experimental treatments in metastatic HER2-positive breast cancer.

Keywords: HER2, metastatic breast cancer, trastuzumab, pertuzumab, lapatinib, trastuzumab-emtansine, triplepositive breast cancer, therapies

Abbreviations: HER2 (1,3,4), human epidermal growth factor receptor 2 (1,3,4); EGFR, human epidermal growth factor receptor (same as HER1); ERBB, human epidermal growth factor receptors family (same as HER family; historically named after erbB gene of avian erythroblastosis virus); $\mathrm{BC}$, breast cancer; $\mathrm{MBC}$, metastatic breast cancer; $\mathrm{EBC}$, early breast cancer; TPBC, triple positive breast cancer; PFS, median progression-free survival; OS, median overall survival; ORR, objective response rate; $\mathrm{BM}$, brain metastases; $\mathrm{BBB}$, blood brain barrier; $\mathrm{AI}$, aromatase inhibitor; ER, estrogen receptor; NK, natural killer cells; ADC, antibody-drug conjugate; TKI, tyrosine kinase inhibitor. 


\section{INTRODUCTION}

Human epidermal growth factor receptor 2 (HER2) was discovered as a human proto-oncogene in 1985 through its homology with an avian viral oncogene v-erbB and with the human EGFR (human epidermal growth factor receptor) gene. In 1987, D. Slamon with co-authors described amplification of HER2 in $\sim 30 \%$ of clinical samples of breast cancers along with its association with aggressive disease and poor survival (1). Trastuzumab, the first HER2-targeted drug, was successfully tested in 2001 (2). Trastuzumab's success triggered development of other HER2targeted agents, including new antibodies (pertuzumab), kinaseinhibitors (lapatinib, neratinib), and antibody-conjugated drugs (trastuzumab-emtanasine). Numerous trials were conducted to select optimal combinations of HER2-targeting agents with cytotoxic therapies. As a result, HER2-positive breast cancer patients now have one of the best survival rates if targeted treatments are applied (3-6).

Human epidermal growth factor receptor 2 is a member of human epidermal growth factor receptors (ERBB) family of membrane tyrosine-kinase receptors, which also include EGFR, HER3, and HER4 (Figure 1A). The generic structure of an ERBB receptor includes extra-cellular ligand-binding domains and an intra-cellular kinase domain. ERBB receptors are activated by a number of peptide ligands, including EGF, TGF-alpha, amphiregulin (for EGFR), and neuregulins (for HER3 and HER4). Ligand binding causes receptor dimerization, activation of the kinase domains, auto-phosphorylation, and initiation of down-stream signaling. This generic scheme has two exceptions: HER3 contains no kinase domain and HER2 has no known ligand. Thus, HER2 and HER3 rely on hetero-dimerization with other ERBB receptors to initiate their cellular effects. The key pathways downstream of HER2 include PI3K and MAPK signaling (Figure 1B) $(7,8)$. MAPK cascade includes sequential activation of RAS-RAF-MEK-ERK, which may stimulate proliferation through increased synthesis of CCND1 mediated by MYC and JUN/FOS transcription factors (9). The PI3K pathway starts with phosphorylation of PIP2 to PIP3, followed by activation of AKT. The de-phosphorylation of PIP3 to PIP2 is catalyzed by PTEN. The effect of PI3K-AKT signaling on proliferation may be mediated by inactivation of the p27 cell cycle inhibitor (10). Upon phosphorylation by AKT, p27 moves from the nucleus to the cytoplasm, thus allowing activation of CCNE1-CDK2 by CCND1-CDK4/6 and promoting G1-to-S cell cycle transition. Along with the effects on cell proliferation, PI3K-AKT signaling stimulates protein biosynthesis and inhibits apoptosis (11). Taken together, such downstream signaling explains the oncogenic effect of HER2 amplification in breast cancer.

\section{DRUGS USED FOR TREATMENT OF HER2-POSITIVE METASTATIC BREAST CANCER}

Current medical treatment of HER2-positive metastatic breast cancer (MBC) combines HER2-targeted agents with cytotoxic and hormonal therapies.

\section{HER2-Targeted Agents}

The HER2-targeted agents currently approved for treatment of $\mathrm{MBC}$, include trastuzumab, pertuzumab, lapatinib, and trastuzumab-emtansine.

\section{Trastuzumab}

Trastuzumab (Herceptin) is a humanized monoclonal antibody binding to the extracellular portion of HER2 close to its transmembrane domain (Figure 1A) (12). It was the first HER2-targeted agent introduced to breast cancer clinics (2) and it remains a key component of the most effective regimens used to treat HER2-positive breast cancers now (13-15). Being an anti-HER2 antibody, trastuzumab has two main mechanisms of action: (i) it suppresses HER2 signaling and (ii) it triggers an antibody-mediated immune response. Studies on cell lines allowed exploration of the effect on the signaling without interference with immune-mediated mechanisms. It was shown that trastuzumab may inhibit HER2 signaling either by destabilizing HER2 heterodimers (12) or by causing internalization of HER2 receptors with subsequent lysosomal degradation (16). In addition, trastuzumab inhibits HER2 signaling by preventing cleavage of HER2 extracellular domain (17): the cleavage of HER2 ectodomain would create a functionally active truncated isoform of HER2 (p95-HER2) (18), which contributes to the tumors progression (19). It was also suggested that trastuzumab may inhibit HER2-cSRC interaction, resulting in the activation of PTEN that attenuates PI3K-AKT signaling (20). Importantly, trastuzumab has no clinical effect on HER2-negative tumors (21). Therefore, all its clinically relevant effects are mediated through HER2.

The contribution of immune mechanisms to the trastuzumab response was confirmed by preclinical and clinical studies of Fc-gamma receptors, involved in the cell-mediated immune response. Thus, trastuzumab effect on HER2-positive xenografts depends on function of Fc-gamma receptors (22), and genetic polymorphisms of Fc-gamma receptors are associated with clinical response to trastuzumab (23). At the same time, it was noted that the contribution of immune mechanisms may be compromised by immunosuppression when trastuzumab is combined with cytotoxic agents (24).

Patent protection of Genentech's trastuzumab (branded as Herceptin) expired in 2014 in Europe and it will expire in 2019 in the US. In 2013, a generic drug MYL-1401O with a protein sequence identical to Herceptin was manufactured by Mylan. After a phase III trial, which confirmed its clinical equivalency to Herceptin (25) in 2017, MYL-1401O (branded as Ogivri, trastuzumab-dkst) was approved by FDA as a biosimilar to Herceptin in the US. A number of other trastuzumab biosimilars have been approved in other countries.

Finally, a recent series of clinical trials demonstrated that trastuzumab can be administered subcutaneously, instead of conventional intravenous administration. This makes trastuzumab treatment more convenient for patients and reduces associated health care costs (26), especially in metastatic settings, where trastuzumab is administered to fragile patients and treatment may last for several years. 


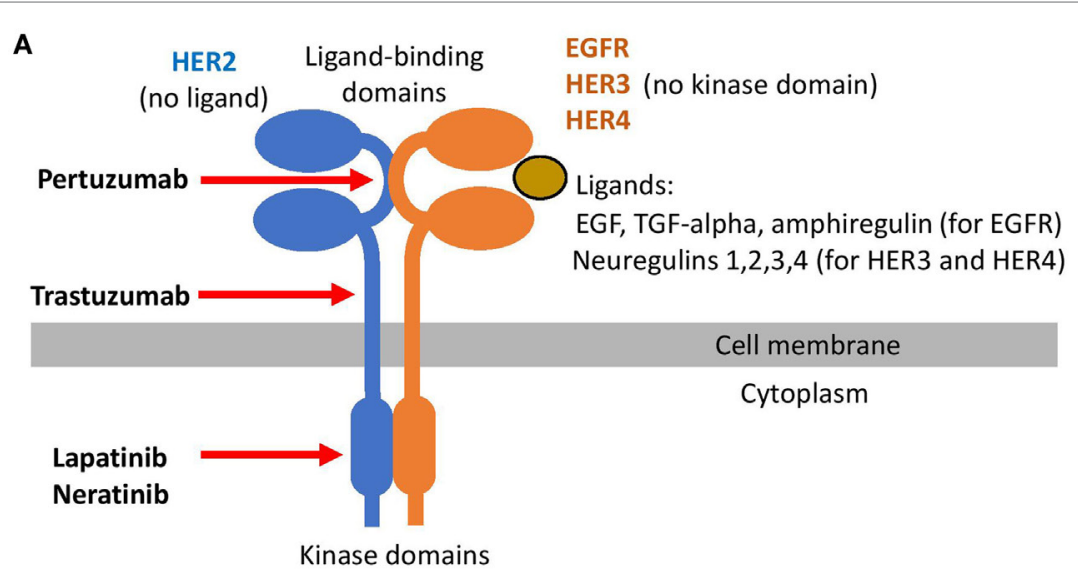

B

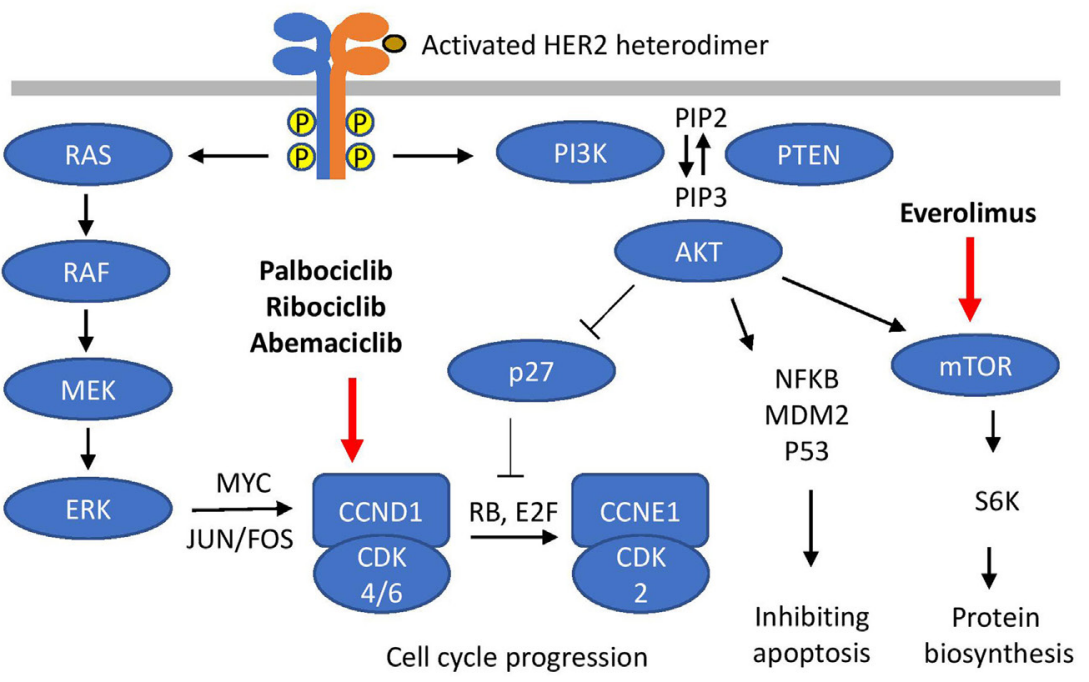

FIGURE 1 | Human epidermal growth factor receptor 2 (HER2) signaling. (A) HER2 hetero-dimerization and HER2 targeting. (B) Signaling downstream of HER2 and its targeting.

\section{Pertuzumab}

Pertuzumab is another monoclonal anti-HER2 antibody. It binds HER2 at a different location than trastuzumab (Figure 1A), primarily preventing formation of HER2-HER3 heterodimers (27). Pertuzumab was initially found to be effective in combination with trastuzumab (so-called "horizontal dual-blockade") (28-30). Later, in a smaller study, pertuzumab was tested as a monotherapy; however, it showed much less efficiency than the combination (31). HER2-HER3 heterodimer is the most potent HER2 heterodimer, and combination of trastuzumab with pertuzumab is currently the most potent combination of HER2targeted agents [as shown in CLEOPATRA trial (32) discussed in more details later].

\section{Lapatinib}

Lapatinib is a small-molecule tyrosine-kinase inhibitor (TKI) targeting intracellular domains of HER2 and EGFR (Figure 1A). While it showed clinical activity in HER2-positive MBC (33, 34 ), it is more toxic and less active than trastuzumab (35). Thus, lapatinib is reserved for use as an addition to trastuzumab (socalled "vertical dual-blockade") (30) in later lines of treatment in patients who cannot tolerate cytotoxic chemotherapy $(36,37)$ or with brain metastases (as discussed in more details in Section “Targeted Treatment of Brain Metastases”) $(36,38)$.

\section{Trastuzumab-Emtansine, T-DM1}

Trastuzumab-emtansine (also known as T-DM1 or Kadcyla) is an antibody-drug conjugate (ADC). This new class of drugs allows for targeted delivery of cytotoxic molecules to the tumor, potentially increasing their efficiency and reducing their toxicity at the same time (39). T-DM1 consists of a highly potent mitotic poison maytansine (DM1) linked to trastuzumab (40). Upon binding with HER2 on tumor cells surface the drug is internalized, maytansine is released from the complex and inhibits microtubule polymerization. Tested in clinic in the 1970s, maytansine displayed an unacceptably high toxicity without the targeted delivery (41). However, trastuzumab-delivered maytansine (T-DM1) showed a good safety profile, causing fewer serious 
adverse effects (grade 3 or worse) than most of other treatment regimens in HER2-positive breast cancer (42-45). A series of phase-III trials showed high clinical efficacy T-DM1 in HER2positive MBC (MARIANNE, EMILIA, and TH3RESA-see Figure 2 and Section "Key Trials With Trastuzumab-Emtansine: TH3RESA, EMILIA, and MARIANNE”). T-DM1 is superior to other current HER2-targeting therapies in the second and later lines in patients pre-treated with trastuzumab or lapatinib $(45,46)$. In first line treatment, T-DM1 is non-inferior to the combination of trastuzumab and taxane, while showing better tolerability (42). T-DM1 is also being tested in combination with pertuzumab and taxanes (47).

\section{Cytotoxic Component}

Trastuzumab shows some activity as a monotherapy in HER2positive MBC (48). However, early addition of cytotoxic chemotherapy to trastuzumab markedly improves both the response rates and the overall survival of $\mathrm{MBC}$ patients (see Initial Trastuzumab Trials and Figure 2: Inoue 2010 and HERTAX trials) $(49,50)$. These clinical data are in agreement with the preclinical models, which showed synergistic and additive interactions of trastuzumab with chemotherapeutic agents used in BC (including platinum agents, taxanes, and anthracyclines) (51). It was suggested that the synergy of trastuzumab with DNA-damaging chemotherapy, such as cross-linking platinum agents, may be explained by the inhibition of HER2-stimulated DNA-repair genes (52). Mechanism of the synergy with taxanes is less clear. However, it was hypothesized (53) that this may be mediated by inhibition of survivin expression $(54,55)$, which is involved in microtubule stabilization during mitosis (56).

A single cytotoxic agent is typically added to HER2-targeted treatment. Use of anthracyclines in HER2-positive MBC is limited because many patients were exposed to anthracyclines in the adjuvant setting, and because of the cumulative cardiotoxicity of anthracyclines. Importantly, the anthracyclines cardiotoxicity overlaps with the toxicity of trastuzumab leading to high rates of heart failure in this combination (57). The cardiotoxicity is substantially reduced if HER2-targeted agents are combined with taxanes instead of anthracyclines. This made taxanes the treatment of choice for the cytotoxic component in the 1st line treatment of HER2-positive MBC (e.g., see the first line trials on Figure 2) (58). The most common taxane regimens include weekly paclitaxel or docetaxel administered at 3 weeks intervals. Nab-paclitaxel may be considered for patients that do not tolerate other taxanes or steroid premedication (e.g., for diabetic patients). Vinorelbine is considered as an alternative to taxanes, since it showed similar efficacy and better tolerability in 1st line HERNATA and VELVET trials $(59,60)$. Attempts of adding a second cytotoxic agent, e.g., combining trastuzumab + taxanes with capecitabine (CHAT trial) or with a platinum salt (BCIRG 007 trial) improved response rates at the expense of higher toxicity. Importantly, the addition of a second cytotoxic agent has provided no survival benefit in these trials $(61,62)$.

There is no strong evidence to select a cytotoxic agent after taxanes. Capecitabine is a convenient oral therapy. Its combination with HER2 targeted agents showed satisfactory clinical efficiency (63-65) and it is frequently used in second line clinical trials (Figure 2). The third line cytotoxic component may include vinorelbine, if not used earlier. At later lines, the most common physician choices include gemcitabine and eribulin (45), allowing the change of cytotoxic agents along several lines of metastatic treatment.

\section{Hormonal Component}

At least 50\% of HER2-positive tumors express hormonal receptors (66). This group of "triple-positive" breast cancers (TPBC) has distinct biology and clinical features $(67,68)$. Current approaches to treatment of metastatic TPBC will be discussed in more details in Section "Treatment of Triple-Positive Breast Cancer." However, combining HER2-targeted and cytotoxic agents with endocrine therapies is one of the obvious options for this group of patients $(14,69)$. It has previously been shown that the addition of HER2-targeting to endocrine treatment improves outcomes in metastatic TPBC (see TAnDEM and EGF30008 trials on Figure 3) $(70,71)$. At the same time, there is much less clinical evidence about the opposite comparison: addition of endocrine therapy to HER2-targeted agents in MBC, although some EBC studies suggest that this may also be beneficial (72).

Until recently, the most common endocrine agents used in $\mathrm{BC}$ clinics were tamoxifen (for pre-menopausal patients) and aromatase inhibitors (AIs: letrozole, anastrozole, and exemestane) for post-menopausal patients. AIs could also be considered for patients of reproductive age after ovarian ablation (e.g., with goserelin or oophorectomy). However, the preferences in selection of hormonal agents are likely to change in the view of several recent clinical trials. First, the FALCON study reported that adequately dosed fulvestrant is more effective than an AI for the first line ER-positive MBC (73). Subsequently, a series of trials showed that the addition of CDK4/6-inhibitors to endocrine treatment significantly improves PFS in metastatic setting (74-76). None of these trials have included HER2-positive patients. However, a number of studies combining HER2-targeting with fulvestrant, AIs, or CDK4/6 inhibitors are already ongoing (PATINA, PATRICIA, and monarcHER trials: NCT02947685, NCT02448420, NCT02675231).

\section{KEY TRIALS SUPPORTING CURRENT CLINICAL PRACTICE}

The results of key trials supporting current clinical practice in HER2-positive MBC are summarized in Figure 2.

\section{Initial Trastuzumab Trials}

The pivotal trial by D. Slamon (2) showed for the first time a significant improvement of both PFS and OS after addition of trastuzumab to cytotoxic chemotherapy in HER2-positive MBC. The cytotoxic component in this trial included anthracyclines or taxanes. In addition to the proof of trastuzumab efficacy, the trial also highlighted the overlapping cardiotoxicity of trastuzumab and anthracyclines (57), paving the way for the wide use of taxanes in combination with trastuzumab in metastatic settings. This also established the practice of monitoring cardiac function during trastuzumab treatment. 


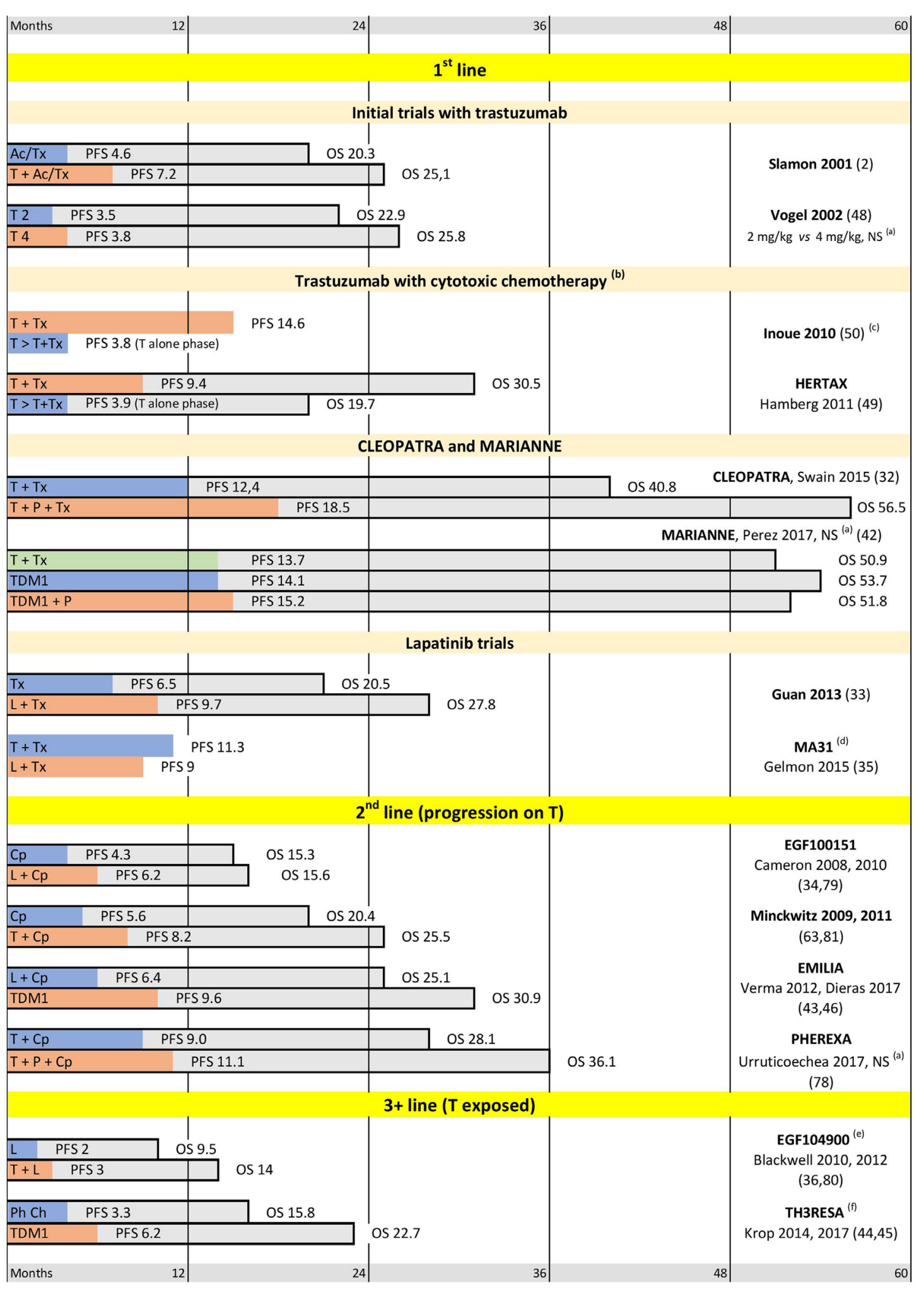

FIGURE 2 | Selected trials supporting current practices in human epidermal growth factor receptor 2 (HER2)-positive metastatic breast cancer (MBC). Abbreviations: T, trastuzumab; P, pertuzumab; L, lapatinib; Tx, taxanes; Cp, capecitabine; Ac, anthracyclines; Ph Ch, physician choice.

(a) Difference between arms is not significant. (b) In the sequential arm Tx is added after progression on T alone. Median progression-free survival (PFS) is shown for T alone phase only. (c) Median overall survival (OS) is in favor of T + Tx, median OS not reached. (d) OS not reported. (e) After 3 T-containing lines on average. (f) After at least 2 metastatic lines. Median PFS and OS are indicated in months. 


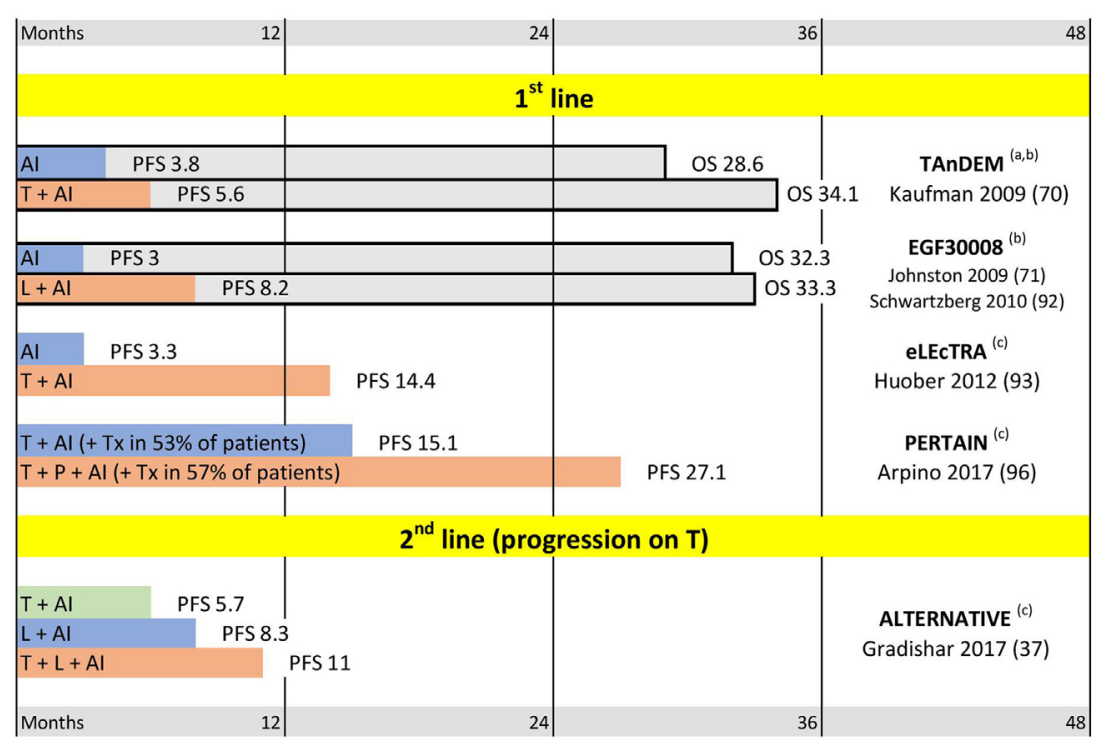

FIGURE 3 | Triple positive breast cancer trials. Abbreviations: T, trastuzumab; P, pertuzumab; L, lapatinib; Al, aromatase inhibitor. (a) Mixed first line and later lines; median progression-free survival (PFS) and median overall survival (OS) for patients with centrally confirmed estrogen receptor. (b) OS trend not significant. (c) OS not reported. Median PFS and OS are indicated in months.

Effectiveness of trastuzumab as a monotherapy was demonstrated in a trial conducted by C. Vogel with co-authors (48). However, the reported PFS was noticeably inferior to the combined regimens reported earlier by $\mathrm{D}$. Slamon. The direct comparison of trastuzumab mono-therapy and trastuzumabtaxane combination could be derived from the two trials reported by K. Inoue and P. Hamberg (HERTAX trial) $(49,50)$. These trials have a very similar design and report similar findings. For ethical reasons, it was not possible to randomly withdraw cytotoxic treatment from MBC patients. So, the comparison was designed as a randomization between simultaneous and sequential administration of cytotoxics. In the simultaneous arms, the taxanes were added to trastuzumab starting from the beginning of the treatment. In the sequential arms, the taxanes were added only after progression on trastuzumab alone. In both trials, the PFS in the trastuzumab-alone phase was markedly shorter than PFS in the trastuzumab-taxane combination. Moreover, the delay in adding cytotoxic treatment significantly reduced OS in both trials. These trials convincingly show that trastuzumab monotherapy may only be reserved for the patients who are not suitable for combined regimens.

\section{Dual-Block by Trastuzumab With Pertuzumab: CLEOPATRA}

Further progress in treatment of HER2-positive MBC was linked to the development of "horizontal dual-blockade." A phase III CLEOPATRA trial randomized 808 patients to either the standard trastuzumab-taxane arm or the new pertuzumab-trastuzumabtaxane combination. The addition of pertuzumab led to statistically and clinically significant improvements in both PFS and OS. In particular, the median overall survival was extended by more than a year and reached in excess of 4.5 years (32). These results are as yet unsurpassed in HER2-positive MBC (if patients are not selected by hormonal receptor level); thus, the CLEOPATRA regimen has substituted trastuzumab-taxane combination as the treatment of choice in first line metastatic treatment. At the same time, it is worth noting that only $\sim 10 \%$ of CLEOPATRA patients were previously exposed to trastuzumab $(13,77)$ and a recent PHEREXA trial reported much smaller benefit from addition of pertuzumab to trastuzumab-exposed $\mathrm{MBC}$ patients in second line treatment (78).

\section{Key Trials With Trastuzumab-Emtansine: TH3RESA, EMILIA, and MARIANNE}

Effectiveness of trastuzumab-emtansine (T-DM1) has been shown in a series of phase III trials, which spanned line1 (MARIANNE), line 2 (EMILIA), and later lines (TH3RESA), EMILIA and TH3RESA demonstrated superiority of T-DM1 over lapatinib + capecitabine and over physician choice in trastuzumab-exposed patients (43-46). This shifted the lapatinib + capecitabine combination to third line, while T-DM1 has been accepted as the second line treatment of choice.

The first line MARIANNE study compared T-DM1 ( \pm pertuzumab) with trastuzumab-taxane combination (which was the first line treatment of choice at the time of the study design). T-DM1 was non-inferior to trastuzumab-taxane and showed a better safety profile (42). No trial yet makes a direct comparison between T-DM1 and CLEOPATRA protocols. It could be noted that MARIANNE enrolled more patients exposed to trastuzumab than CLEOPATRA ( $\sim 30$ and $\sim 10 \%$, respectively) (13, 77 ). However, in view of the clear superiority of CLEOPATRA protocol over trastuzumab-taxane, T-DM1 remains reserved for second line treatment (although there is no data about T-DM1 efficiency in pertuzumab-exposed patients). 


\section{Selected Lapatinib Trials}

Different lapatinib-containing combinations were tested in different metastatic settings. Adding lapatinib to chemotherapy significantly improves PFS and OS in first and second lines of treatment if compared to placebo (Guan-2013 and EGF00151 studies, respectively) $(33,34,79)$. However, a comparison with trastuzumab showed that lapatinib-taxanes combination has lower efficacy and higher toxicity than combination of taxanes with trastuzumab (MA-31 study) (35). Similarly, despite the proven activity of the lapatinib-capecitabine protocol in the second line (EGF00151 study) $(34,79)$, this combination was inferior to T-DM1 in EMILIA trial $(43,46)$. Thus, currently lapatinib is reserved for third and later lines of treatment. Utility of lapatinib for patients with brain metastases will be discussed later in Section “Targeted Treatment of Brain Metastases." Importantly, lapatinib is more effective in combination with trastuzumab (the "vertical dual blockade") than taken alone, even in trastuzumabexposed patients (see EGF104900 and ALTERNATIVE trials on Figures 2 and 3) $(36,37,80)$. This is in agreement with other studies confirming efficacy of trastuzumab beyond progression $(63,81)$.

\section{CURRENT CONSENSUS GUIDELINES}

Initial HER2-targeting clinical practices were shaped by trials that demonstrated effectiveness of adding trastuzumab or lapatinib to chemotherapy in HER2-positive MBC $(2,33)$. It was also established that HER2-targeting should continue beyond progression through multiple lines of treatment $(63,81)$. Thus, the general consensus at the time was that trastuzumab + taxanes could be considered as the first line treatment of choice $(58,82)$, followed by lapatinib- and capecitabine-containing combinations in second line (34). Overall, this practice was adopted from the time of the pivotal trial of D. Slamon in 2001 (2) until the recent development of the horizontal dual-blockade (trastuzumab + pertuzumab) and T-DM1. The first results of a large T-DM1 trial in HER2-positive MBC (EMILIA PFS results) were published in 2012 (43). Similarly, the results of TH3RESA, MARIANNE, and CLEOPATRA were published between 2014 and $2017(32,42,44,45)$. These trials called for a reassessment of previous clinical practices and led to updates in a number of guidelines released by expert panels around the world. The new consensus was set by the ASCO guidelines of 2014 (69), which was broadly followed by a number of other expert panels, including NCCN, ESMO, AGO and SEOM, to mention just a few within the past 3 years $(13-15,77,83-85)$. The most commonly supported sequencing is summarized in Table 1 . The guidelines agree that (i) dual-blockade with trastuzumab + pertuzumab is the preferred regimen for first line treatment; (ii) T-DM1 is the second line treatment of choice, and (iii) addition of lapatinib may be considered in the later lines. Pertuzumab-containing regimens and T-DM1 should also be considered in later lines for the patients, who have not received them earlier. Along with the current consensus, the guidelines highlight that the fast and simultaneous development of new HER2-targeted agents lead to a shortage of evidence regarding the use of these agents. Thus, more data is needed about the efficacy of trastuzumab-pertuzumab
TABLE 1 | Current consensus sequencing of metastatic treatment in human epidermal growth factor receptor 2 (HER2)-positive metastatic breast cancer (MBC).

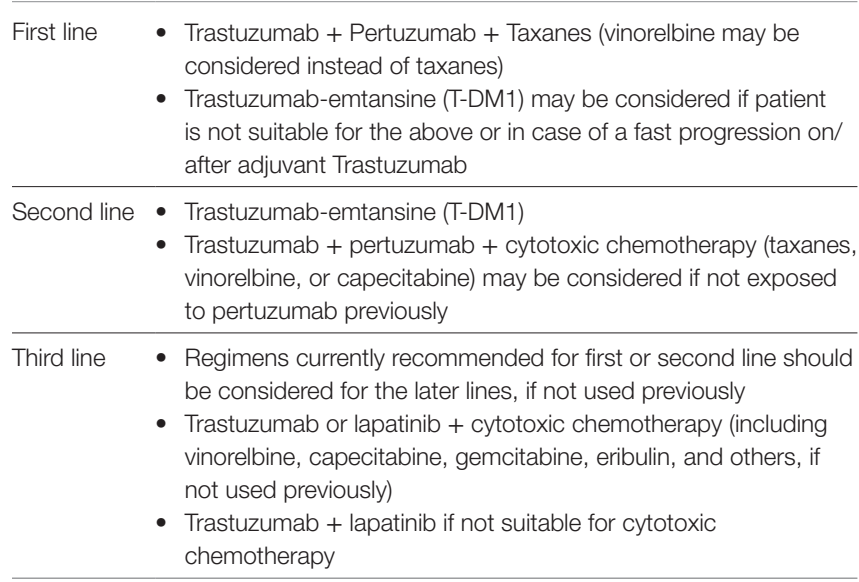
Addition of endocrine therapy to HER2-targeted agents should be considered at any line after completion of cytotoxic chemotherapy in ER-positive patients. Based on ASCO 2014 (69), NCCN 2017 (14), ESMO-ABC3 2017 (13, 77), AGO 2015 (85), and SEOM 2015-2017 (15, 83, 84) guidelines.

dual-block in trastuzumab-exposed patients. There is no data yet about efficacy of T-DM1 on pertuzumab-exposed patients or about the performance of lapatinib- and capecitabine-containing regimens on patients pre-treated with T-DM1.

\section{REMAINING QUESTIONS}

In addition to the shortage of data about novel pertuzumab and TDM1-containing regimens, there is a list of other questions, which need to be further studied to improve treatment of HER2-positive MBC. These questions include (i) use of hormonal therapy in triple-positive breast cancers, (ii) treatment of brain metastases, (iii) assessment and conversion of HER2 expression in metastatic lesions, (vi) duration of treatment for metastatic patients with stable and complete response, (v) shortage of evidence about cancers resistant to adjuvant treatment, and (vi) treatment adjustments for elderly patients. The first two questions are of special importance in this list because they immediately affect treatment for a large proportion of HER2-positive MBC patients.

\section{Treatment of Triple-Positive Breast Cancer}

More than $50 \%$ of HER2-positive tumors also express estrogen receptors (66). These tumors are being increasingly recognized as a distinct group of breast cancers: "Triple Positive Breast Cancer" (TPBC) $(68,86,87)$, whose unique biology is shaped by a complex interplay of HER2 and ER signaling (88-91). Optimal management of TPBC lies on the border between endocrine and HER2-targeted treatments. However, till recently, HER2-positive tumors have usually been excluded from endocrine trials, and studies of HER2-targeted agents often reported results without splitting them into ER-positive and ER-negative subgroups. So far, only a limited number of trials focused on metastatic TPBC patients (Figure 3). Three trials (TANDEM, EGF30008, and ELECTRA) showed that addition of HER2-targeting to 
endocrine treatment significantly prolongs PFS, although the OS improvements in these trials did not reach statistical significance $(70,71,92,93)$. No randomized study has yet performed the opposite comparison: the addition of endocrine treatment to HER2-targeting agents. However, a retrospective analysis suggests that this may improve the results of treatment (72). Endocrine treatment has low toxicity, and multiple lines of evidence suggest that ER-positive tumors may have inferior response to cytotoxic treatment $(94,95)$. Taken together, these data justify addition of endocrine treatment whenever possible for ER-positive breast cancer, which led to the current ASCO and ESMO recommendations to add endocrine agents to the treatment for most TPBC patients in metastatic setting. Addition of the hormonal agents to HER2-targeted treatment is recommended after completion of cytotoxic chemotherapy $(13,69,77)$. Importantly, the guidelines emphasize that addition of endocrine therapy is not based on direct evidence. Also, they provide no reason why endocrine therapy should be delayed until completion of cytotoxic treatment.

The shortage of evidence about TPBC patients is being addressed by several recent and ongoing clinical trials summarized in Figure 3 and Table 2. The recently reported PERTAIN trial was designed to evaluate the effect of horizontal dualblockade in metastatic TPBC (96). The control arm included trastuzumab + aromatase inhibitor, while the experimental arm added pertuzumab to the combination. Induction chemotherapy with taxanes prior the aromatase inhibitor was permitted at the discretion of the investigator (and was applied in $50 \%$ cases in both arms). The analysis showed a significant increase in PFS after addition of pertuzumab. However, PERTAIN's results may also be considered in a wider context. It was the first controlled trial that reported results of combining HER2-targeting, cytotoxic, and hormonal treatment at the same time-and the effect of such combination in both PERTAIN arms was unprecedented. Thus, median PFS in the experimental arm exceeded 2 years (27.1 months), which is an exceptional result for a metastatic cancer. Although PFS in the control PERTAIN's arm was "just" 15.1 month, it was comparable to PFSs reported in experimental arms by MARIANNE and CLEOPATRA (14.1 and 18.5 months) despite the fact that only half of PERTAIN patients received taxanes. Another interesting observation about PERTAIN was the very fact that investigators opted not to include taxanes in nearly $50 \%$ of cases, even though it was permitted by the protocol. The treatment sub-groups analysis (for patients with and without taxanes) and overall survival data of PERTAIN trial are awaited with interest.

The second recently reported metastatic TPBC trial is ALTERNATIVE (37). The study enrolled TPBC patients progressing on a (neo)adjuvant/first line trastuzumab + chemotherapy regimen. The treatment included three arms: trastuzumab vs. lapatinib vs. trastuzumab + lapatinib. Aromatase inhibitors were added in each arm. Patients intended for cytotoxic chemotherapy were excluded from this trial. The vertical dual blockade (trastuzumab + lapatinib combination) showed superior PFS as compared with lapatinib or trastuzumab alone $(11,8.3$, and 5.7 months, respectively). Again, despite the absence of cytotoxic treatment in this trial, the 11 months median PFS achieved in
TABLE 2 | Ongoing clinical trials in metastatic triple positive breast cancer (TPBC).

\begin{tabular}{ll}
\hline PATRICIA & Postmenopausal patients exposed to trastuzumab in \\
NCT02448420 & previous metastatic setting \\
Phase II & 3 arms: \\
- Estrogen receptor (ER) negative, human epidermal & growth factor receptor 2 (HER2) positive patients: \\
& palbociclib + trastuzumab \\
- & ER positive, HER2 positive patients: \\
& palbociclib + trastuzumab \\
- & ER positive, HER2 positive patients: \\
& palbociclib + trastuzumab + letrozole \\
Expected completion: 2019
\end{tabular}

\begin{tabular}{ll}
\hline monarcHER & TPBC after at least two HER2-targeted therapies for \\
NCT02675231 & advanced disease \\
Phase II & 3 arms: \\
& - Abemaciclib + Trastuzumab + Fulvestrant \\
- Abemaciclib + Trastuzumab \\
- Trastuzumab + Chemotherapy of physician choice \\
Expected completion: 2018-2019
\end{tabular}

\begin{tabular}{ll}
\hline PATINA & First line metastatic TPBC patients \\
NCT02947685 & 2 arms: \\
Phase III & Palbociclib + Anti-HER2 therapy + Endocrine \\
& therapy \\
- & Anti-HER2 therapy + Endocrine therapy \\
Induction cytotoxic chemotherapy is allowed prior & randomization \\
& Expected completion: 2020-2024
\end{tabular}

DETECT-V/CHEVENDO TPBC patients with up to two prior therapies for the NCT02344472 metastatic disease

Phase III 2 arms:

- Trastuzumab + Pertuzumab + Cytotoxic chemotherapy

- Trastuzumab + Pertuzumab + Endocrine therapy

Quality of life and adverse effects as a primary outcome

Expected completion: 2021

\begin{tabular}{ll}
\hline SYSUCC-002 & First line metastatic TPBC patients \\
NCT01950182 & 2 arms: \\
Phase III & - Trastuzumab + Cytotoxic chemotherapy \\
& - Trastuzumab + Endocrine therapy \\
& Expected completion: 2018 \\
\hline NCT03054363 & Tucatinib in combination with Palbociclib and \\
Phase Ib-II & Letrozole for first or second line metastatic TPBC. \\
& In 2017, the study is not yet open for participant \\
& recruitment \\
\hline
\end{tabular}

trastuzumab + lapatinib + AI arm was among the best reported in HER2-positive second line trials, such as EMILIA (9.6 months PFS for T-DM1) or PHEREXA (11.1 months for horizontal dualblock + taxanes) $(43,78)$. It is not yet clear whether the exceptional PFS results reported by PERTAIN and ALTERNATIVE reflect the favorable intrinsic properties of TPBC or the good response to combined HER2- and ER-targeting; and these trials have not yet reported the overall survival data. However, these trials already provide interesting and encouraging data about new treatments and outcomes in metastatic TPBC. 
A significant progress has been made over the recent years in the treatment of metastatic ER-positive HER2-negative breast cancer: fulvestrant $(500 \mathrm{mg})$ has been promoted to first line metastatic hormonal treatment (73) and CDK4/6 inhibitors have been established as a standard addition to endocrine agents (97). This progress triggered a series of trials testing whether these new approaches could be beneficial for TPBC patients (Table 2). Thus, phase II PATRICIA and monarcHER trials are studying addition of CDK4/6 inhibitors to trastuzumab (with or without hormonal treatment) in patients progressing after previous trastuzumabcontaining metastatic regimens. Phase III PATINA trial studies addition of CDK4/6 inhibitors to HER2-targeted agents in first line metastatic treatment (with or without hormonal therapy). Two other ongoing trials compare endocrine and cytotoxic therapies in combination with HER2 targeting in metastatic TPBC (DETECT-V and SYSUCC-002 trials, see details in Table 2). All these trials are currently enrolling patients. The results are expected between 2018 and 2024.

Taken together, the recently reported and ongoing trials in metastatic TPBC will provide evidence to support new treatment standards for this group of patients. Finally, it could be noted that most metastatic TPBC patients were exposed to previous endocrine treatments in a (neo)adjuvant setting and/or in previous metastatic lines. Thus, testing for activating mutations in ligandbinding domain of estrogen receptor may be helpful for rational selection of the endocrine component of their treatment (98).

\section{Targeted Treatment of Brain Metastases}

Brain metastases (BM) have a distinct biology and poor prognosis $(99,100)$. Currently, symptomatic BM is reported in $20-40 \%$ of HER2-positive MBC $(101,102)$. Additionally, up to $10 \%$ of patients may have asymptomatic BM detectable on autopsy (100). Incidence of BM is significantly higher in ER-negative than in ER-positive disease (99). Treatment of BM is based on radiotherapy and surgery, supported by systemic therapies based on cytotoxic and targeted agents (103-105). The backbone systemic therapy could be combined with additional medication (such as corticosteroids and anti-epileptic drugs) that is beyond the scope of this review (106). Paradoxically, treatment with trastuzumab increases incidence of brain metastases (107-110), while prolonging the time to BM (110) and overall survival of patients with BM $(108,111)$. This is commonly explained by trastuzumab's success in suppressing extracranial metastatic sites, which allows time for brain metastases to develop and manifest clinically. Importantly, while achieving good extra-cranial control, trastuzumab has limited effect on brain metastases themselves because of its poor permeability through the blood-brain barrier (BBB). Thus, under conditions of unimpaired $\mathrm{BBB}$, trastuzumab's concentration in cerebrospinal fluid could be 420 times below its concentration in serum; even when $\mathrm{BBB}$ is compromised by irradiation, the concentration of trastuzumab in brain is still about 50 times lower than in blood (112). In contrast, small-molecule TKIs, like lapatinib, penetrate BBB much better (113). This raised expectations about a possible special role for TKIs in BM treatment and encouraged a number of small trials evaluating effect of lapatinib on BM in heavily pre-treated HER2-positive MBC patients (114). In these trials, lapatinib alone showed low CNS response rates
(2-6\%) and low PFS (up to 3 months). However, when lapatinib was combined with capecitabine, the objective response rates rose to $18-38 \%$ and PFS to $\sim 5$ months. For comparison, CNS PFS reported for cytotoxic chemotherapies alone did not exceed 4 months at the time (114). Taken together, these trials suggested some CNS benefit from addition of lapatinib, although of a limited clinical significance in pre-treated population. In 2013, a small single-arm open-label trial tested lapatinib + capecitabine combination on patients with previously untreated brain metastases (LANDSCAPE trial). It reported 66\% CNS ORR and median PFS of 5.5 months (115). Excellent ORR in LANDSCAPE trial was reflected in some guidelines, including ASCO-2014 and EANO-2017 (104, 105). However, a later CEREBEL trial failed to show superiority of lapatinib + capecitabine over trastuzumab in preventing BM (38). Although interpretation of the CEREBEL trial is complicated by the unexpectedly low rates of BM (3-5\%), this trial brought some caution toward the lapatinib + capecitabine regimen. More importantly, a sub-analysis of EMILIA trial directly showed that T-DM1 provides better OS than lapatinib + capecitabine in patients with BM (116). Similarly, trastuzumab and/or pertuzumab trials showed improvement in overall survival for patients with BM $(111,117)$, despite the low penetrance of $\mathrm{BBB}$ for these drugs. This is commonly explained by the importance of extracranial control in patients with $\mathrm{BM}$. Building on this evidence, the most recent $\mathrm{ABC}-3$ guideline from ESO-ESMO does not recommend a change of systemic treatment for patients with BM, providing stable extracranial disease $(13,77)$. A trastuzumab-containing regimen is still essential for patients with BM because of its contribution to extracranial control. However, considering the low penetrance of BBB for trastuzumab, patients with BM may be encouraged to participate in clinical trials $(85,105)$. Trials of new TKIs, such as neratinib, are underway (118). Future trials combining small molecules and antibody-based agents may also be expected, as well as the trials of new methods to increase BBB permeability (119).

\section{THERAPIES UNDER DEVELOPMENT}

The HER2-targeted treatments developed over the past 20 years converted the unfavorable natural history of HER2-positive BC into favorable clinical outcomes. At the same time, the metastatic disease still remains incurable for most patients. The innate and acquired resistance to existing therapies requires development of novel agents and strategies. The range of new therapies that are currently under development for HER2-positive MBC include (i) new TKIs targeting ERBB receptors and inhibitors of their down-stream signaling, (ii) inhibitors of cell cycle, HSP90, and angiogenesis, (iii) HER2-targeted drug delivery, and (iv) new antibodies and immunotherapy aimed at HER2-positive BC.

\section{New ERBB-Targeting TKIs}

Neratinib is classified as a pan-ERBB TKI because it binds and irreversibly inhibits all ERBB receptors except HER3 $(118,120)$. On the basis of ExteNET study, neratinib has been recently approved by the FDA for extended post-trastuzumab adjuvant treatment (121). However, neratinib yet failed to show superiority over comparators in metastatic settings. Comparison of neratininb 
with trastuzumab (both in combination with taxanes) in first line treatment was performed by NEfERT trial, which reported identical PFS in both arms (12.9 months) and much higher toxicity in the neratinib arm (grade 3 diarrhoea developed in up to $30 \%$ of patients) (122). In a second line trial that compared neratinib monotherapy with the combination of lapatinib + capecitabine, the neratinib arm showed shorter PFS and OS than the combination (PFS 4.5 vs 6.8 and OS 19.7 vs 23.6 months, respectively, differences between arms are not significant) (123). At the same time, a sub-analysis of NEfERT-T trial showed that neratinib was more effective against brain metastases (relative risk of CNS recurrences $0.48, p=0.002$ ). Another pan-ERBB TKI, afatinib, was tested in several breast cancer trials, and has progressed to a phase III trial in the first line metastatic setting (LUX-Breast 1). However, this trial was stopped after an interim assessment showed that afatinib outcomes were less favorable than trastuzumab (124). Neither neratinib nor afatinib are currently approved for treatment of HER2-positive MBC outside of clinical trials (125), although new trials of neratinib may be expected in patients with brain metastases.

As an alternative to pan-ERBB inhibitors, a selective HER2specific TKI was developed by Array BioPharma (Tucatinib, formerly known as ONT-380 or ARRY-380). It was expected to reduce the off-target effects and high toxicity common for dualand pan-ERBB inhibitors. In a phase I trial, Tucatinib showed promising efficacy and safety profile (126). It also showed capacity to penetrate the $\mathrm{BBB}$ and some promising results in patients with brain metastases (127). In view of these phase I results, a phase II trial has been recently initiated, which combines tucatinib with trastuzumab and capecitabine in HER2-positive MBC (HER2CLIMB, NCT02614794). Another recently initialed tucatinib trial combines it with $\mathrm{CDK} 4 / 6$ and aromatase inhibitors in metastatic TPBC patients (NCT03054363). The results of these trials are awaited with interest.

\section{PI3K and mTOR Inhibitors}

$\mathrm{PI} 3 \mathrm{~K}$ and $\mathrm{mTOR}$ are key components in signaling downstream of HER2 (Figure 1B). The m-TOR inhibitor everolimus has been extensively studied in breast cancer, and it is approved for treatment of ER-positive HER2-negative $\mathrm{BC}$ on the basis of BOLERO-2 trial (128). However, it showed less encouraging results in two large phase III trials in HER2-positive MBC (BOLERO-1 and BOLERO-3). BOLERO-1, which studied addition of everolimus to trastuzumab + taxanes in first line metastatic treatment, reported that everolimus was associated with increased toxicity without any improvement in either PFS or OS $(129,130)$. BOLERO-3 tested addition of everolimus to trastuzumab + vinorelbine in second line metastatic treatment for patients previously exposed to trastuzumab and taxanes. The addition of everolimus in the BOLERO-3 led to a statistically significant improvement of PFS (131). However, numerically the median PFS was prolonged by less than 2 months (7.0 vs 5.8 months) and there was no improvement in OS (132). A joint analysis of BOLERO-1 and BOLERO-3 was conducted in search for biomarkers to select patients benefiting most from treatment with everolimus. It showed that somatic mutations in the PI3K pathway (PIK3CA, PTEN, and AKT1 genes) could be used to predict response, and that everolimus benefit was mainly limited to ER-negative patients (133).

Similarly, several PI3K inhibitors which have been previously studied in ER-positive HER2-negative BC, are currently at early stages of testing in HER2-positive disease (including buparlisib (134), alpelisib (135), taselisib-NCT02390427, and pictilisibNCT00960960). Like everolimus, none of these PI3K inhibitors is yet recommended for HER2-positive patients outside of clinical trials. However, they may be used in future personalized treatment of HER2-positive MBC if companion biomarkers are developed to select responsive patients.

\section{CDK4/6 Inhibitors}

CDK4 and CDK6 are partners of Cyclin D1, the key cell cycle regulator controlling G1-S transition. Activated by Cyclin D1, CDKs 4/6 phosphorylate RB protein, which in turn releases E2F from RB-E2F complexes leading to activation of Cyclin E and downstream cell cycle machinery (Figure 1B) (136). Cyclin D1 is frequently amplified in human cancers, including breast cancer (137). Surprisingly, despite the central role of Cyclin D1 in cell cycle regulation, mice lacking Cyclin D1 are viable and resistant to HER2(neu)-induced breast cancers (but not to breast cancers induced by MYC) (138). HER2-amlpified breast cancer cell lines are among the most sensitive to CDK4/6 inhibition (74). Along with the involvement in HER2-dependent carcinogenesis, Cyclin D1 also plays a key role in signaling downstream of estrogen receptor (139). These molecular findings triggered interest in CDK4/6 inhibitors for breast cancer treatment, culminating in several recently published large phase III clinical trials (PALOMA-2/3, MONALEESA-2, and MONARCH-2) that tested addition of different CDK4/6 inhibitors (palbociclib, ribociclib, and abemaciclib, respectively) to hormonal therapies in ER-positive HER2-negative MBC $(75,97,140,141)$. The success of these trials led to regulatory approvals and supported a wave of interest in CDK4/6 inhibitors for treatment of HER2-positive disease. Several ongoing CDK4/6 trials in HER2-positive MBC were discussed in the TPBC section of this review (PATRICIA, monarcHER, and PATINA, see Table 2). Notably, one of the PATRICIA arms also includes ER-negative patients. It was also reported that abemaciclib has good CNS penetration, showing similar concentrations in plasma and brain (142). Importantly, the effect of CDK4/6 inhibitors requires intact $\mathrm{RB}$ protein expression (143). Thus, RB loss (and other RB mutations) should be monitored before treatment with CDK4/6 inhibitors and after progression on treatment. At present, CDK4/6 inhibition is perceived as one of the most promising new directions in the treatment of HER2-positive MBC, which may soon be used in clinical practice (at least in TPBC patients) (144).

\section{Inhibitors of HSP90 and Angiogenesis}

Experimental studies suggested a potential role for HSP90, angiogenesis, and topoisomerase inhibitors in treatment of different types of cancer. However, clinical trials have not yet justified including these drugs into routine clinical practice in HER2positive MBC.

HSP90 is a chaperon protein, which is required for proper folding and function of hundreds of its client proteins (145), 
including HER2 and its key downstream targets (146). Preclinical studies reported anti-tumor activity of HSP90 inhibitors on a wide range of BC cells, with HER2-positive cell lines being particularly sensitive (147). In 2011, a phase II clinical trial studied effect of an HSP90 inhibitor tanespimycin on 31 HER2-positive MBC patients who previously progressed on trastuzumab (148). It reported objective responses to the tanespimycin + trastuzumab combination in $22 \%$ of the patients with median PFS of 6 months and median OS of 17 months. While this was a positive result, the efficiency of tanespimycin + trastuzumab looked modest in comparison to trastuzumab-emtansine reported shortly afterward (EMILIA trial first reported in 2012: PFS 9.6 months and OS 30.9 months) (43). Another HSP90 inhibitor showed limited efficacy in HER2-positive MBC in a phase II trial reported in 2013 (149). No further clinical trials of HSP90 inhibitors were reported in HER2-positive MBC since then. However, the overall interest and experimental studies of HSP90 are continuing, with focus on biological complexity of HSP90 functions in cancer (145, 150, 151).

Similarly, there were attempts to inhibit angiogenesis in HER2-positive metastatic cancer. Angiogenesis is highly specific for tumor tissue in adults (152). HER2 overexpression stimulates VEGF expression in breast cancer (153), potentially leading to poorer clinical outcomes (154). Phase I and II trials showed that inhibitors of angiogenesis (such as VEGF inhibitor bevacizumab) may have effect on some HER2-positive MBC (155). However, a phase III clinical trial of bevacizumab in HER2-positive MBC failed to detect an improvement in PFS in first line treatment (AVEREL trial) (156), which was consistent with an unsuccessful adjuvant trial in HER-positive EBC (BETH trial) (157). Since 2010, the FDA does not approve bevacizumab for any form of breast cancer. The current studies of angiogenesis inhibitors in breast tumors are focused on the search for a sub-set of tumors that may be responsive to this class of drugs $(158,159)$.

\section{HER2-Targeted Drug Delivery and Immunotherapies}

The success of T-DM1 stimulated development of other HER2targeted antibody-drug-conjugates (ADC). The main directions in development of new ADC include (i) new targeting antibodies, (ii) new conjugated drugs, and (iii) increasing the drug-toantibody ratio. Thus, DS-8201 is a conjugate of trastuzumab with a topoisomerase-1 inhibitor (160). Its development progressed to a phase I clinical trial, which confirmed safety and potential efficacy in T-DM1-exposed patients (161). Another novel ADC is XMT-1522. Its antibody part targets a new epitope on HER2, thus avoiding potential competition for epitopes with trastuzumab or pertuzumab if used in combination. Moreover, each XMT-1522 antibody is conjugated with 15 molecules of a proprietary cytotoxic component auristatin. XMT-1522 showed significantly higher potency than T-DM1 in preclinical models (162). Currently, it is being tested in a phase I clinical trial (NCT02952729).

An alternative approach to HER-2 targeted drug delivery was tested by an antibody-conjugated liposomal doxorubicin formulation called MM-302. It delivered drug to tumor in liposomes tagged with anti-HER2 antibodies. The intention was to expand doxorubicin therapeutic range by avoiding its cardiotoxicity. A recent phase II trial (HERMIONE) compared the combination of trastuzumab with MM-302 against a combination of trastuzumab with cytotoxic chemotherapy of physician choice in heavily pretreated HER2-positive MBC patients (163). MM-302 was well tolerated. However, the trial has been terminated after an interim review showed no efficacy benefit over the comparator. Another new strategy is non-antibody targeting. Thus, S. Pallerla with coauthors designed a HER2-targeted doxorubicin-peptidomimetic conjugate (164). The targeting is achieved by a short peptide that selectively binds to HER2. The compound is still in an early preclinical phase. An interesting approach was reported by X. Kang with co-authors, who conjugated trastuzumab with gold nanoparticles, which allowed HER2-targeted photothermal tumor destruction (165). Potentially, this method avoids any chemotherapy-associated toxicity. However, the studies are also still at a preclinical phase (testing on xenografts).

Finally, it is well established that immune mechanisms may contribute to response to trastuzumab (see Trastuzumab Section) $(22,23)$. A new antibody, magretuximab (MGAH22), has been designed to enhance the antibody-dependent cell-mediated cytotoxicity against HER2-positive tumor cells. Its Fab region targets the same epitope as trastuzumab. However, its Fc region was modified to increase affinity to activating Fc-receptors on NK-cells and macrophages. Magretuximab was well tolerated and showed promising efficacy as a monotherapy in phase I clinical trial (166). A phase III trial, SOPHIA, is testing a combination of magretuximab + cytotoxic chemotherapy in trastuzumabexposed MBC patients (167). An alternative approach is used in ertumaxomab: an engineered multi-functional antibody that simultaneously binds HER2, CD3, and the Fc-gamma-receptors. Potentially, this might promote immune response by bringing the tumor cell, T-cell, and accessory immune cells together. So far, ertumaxomab has been tested in two phase I clinical trials that reported encouraging safety and efficacy $(168,169)$. Other immunotherapy approaches that already reached at least phase I-II trials, include immune checkpoints inhibitors (PANACEA and KATE2 trials: NCT02129556, NCT02924883), T-cell therapies (170), and vaccines (171). Overall, despite still being at early stages of development, the new HER2-targeted drug delivery systems and immunotherapies show promise and may extend our armamentarium for treating HER2-positive MBC in future.

\section{CONCLUSION}

High expression or amplification of HER2 defines a distinct group of breast cancers. 20 years ago it was considered as an intrinsically aggressive subtype associated with poor prognosis (1). However, the tumor dependence on HER2 has also provided a target for treatments, which dramatically changed the outcomes for this type of disease. Now, HER2-positive breast cancer is considered as a favorable subtype (3-6) with about $70 \%$ of EBC patients reaching 10-year disease-free survival after the current HER2-targeted adjuvant treatments (172). While the metastatic HER2-positive $\mathrm{BC}$ remains incurable, HER2-targeting significantly prolonged the life of these patients too, with median overall survival 
exceeding 4 years in recent clinical trials $(32,42)$. HER2-targeted agents currently approved for metastatic breast cancer, include trastuzumab, pertuzumab, trastuzumab-emtansine, and lapatinib. They are used in different combinations with each other and with other chemotherapeutic agents. The recent progress in treatment of HER2-positive MBC was achieved by the development of horizontal dual blockade (pertuzumab + trastuzumab) (32) and by HER2-targeted drug delivery (trastuzumab-emtansine) (42). The current studies focus on (i) accumulating new evidence about recently established treatment regimens, (ii) treatment stratification by expression of estrogen receptors, (iii) treatment of brain metastases, (iv) development of new tools for HER2targeting (new TKIs, antibodies, antibody-drug conjugates, and immunotherapies), and on (v) targeting pathways downstream of

\section{REFERENCES}

1. Slamon DJ, Clark GM, Wong SG, Levin WJ, Ullrich A, McGuire WL. Human breast cancer: correlation of relapse and survival with amplification of the HER-2/neu oncogene. Science (1987) 235(4785):177-82. doi:10.1126/ science. 3798106

2. Slamon DJ, Leyland-Jones B, Shak S, Fuchs H, Paton V, Bajamonde A, et al. Use of chemotherapy plus a monoclonal antibody against HER2 for metastatic breast cancer that overexpresses HER2. N Engl J Med (2001) 344(11):783-92. doi:10.1056/NEJM200103153441101

3. Mendes D, Alves C, Afonso N, Cardoso F, Passos-Coelho JL, Costa L, et al. The benefit of HER2-targeted therapies on overall survival of patients with metastatic HER2-positive breast cancer - a systematic review. Breast Cancer Res (2015) 17:140. doi:10.1186/s13058-015-0648-2

4. Adusumilli P, Konatam ML, Gundeti S, Bala S, Maddali LS. Treatment challenges and survival analysis of human epidermal growth factor receptor 2-positive breast cancer in real world. Indian J Med Paediatr Oncol (2017) 38(1):22-7. doi:10.4103/0971-5851.203511

5. Sundquist M, Brudin L, Tejler G. Improved survival in metastatic breast cancer 1985-2016. Breast (2017) 31:46-50. doi:10.1016/j.breast.2016. 10.005

6. Dawood S, Broglio K, Buzdar AU, Hortobagyi GN, Giordano SH. Prognosis of women with metastatic breast cancer by HER2 status and trastuzumab treatment: an institutional-based review. J Clin Oncol (2010) 28(1):92-8. doi:10.1200/JCO.2008.19.9844

7. Citri A, Yarden Y. EGF-ERBB signalling: towards the systems level. Nat Rev Mol Cell Biol (2006) 7(7):505-16. doi:10.1038/nrm1962

8. Arteaga CL, Engelman JA. ERBB receptors: from oncogene discovery to basic science to mechanism-based cancer therapeutics. Cancer Cell (2014) 25(3):282-303. doi:10.1016/j.ccr.2014.02.025

9. Wee P, Wang Z. Epidermal growth factor receptor cell proliferation signaling pathways. Cancers (Basel) (2017) 9(5):52. doi:10.3390/cancers9050052

10. Liang J, Zubovitz J, Petrocelli T, Kotchetkov R, Connor MK, Han K, et al. $\mathrm{PKB} /$ Akt phosphorylates p27, impairs nuclear import of p27 and opposes p27-mediated G1 arrest. Nat Med (2002) 8(10):1153-60. doi:10.1038/nm761

11. Liu P, Cheng H, Roberts TM, Zhao JJ. Targeting the phosphoinositide 3-kinase pathway in cancer. Nat Rev Drug Discov (2009) 8(8):627-44. doi: $10.1038 / \mathrm{nrd} 2926$

12. Schmitz KR, Ferguson KM. Interaction of antibodies with ErbB receptor extracellular regions. Exp Cell Res (2009) 315(4):659-70. doi:10.1016/j. yexcr.2008.10.008

13. Cardoso F, Costa A, Senkus E, Aapro M, Andre F, Barrios CH, et al. 3rd ESO-ESMO international consensus guidelines for advanced breast cancer (ABC 3). Breast (2017) 31:244-59. doi:10.1016/j.breast.2016.10.001

14. NCCN. Breast Cancer Guidelines, Ver. 2.2017. (2017). Available from: www. nccn.org (Accessed: May 21, 2017).

15. Mestres JA, iMolins AB, Martinez LC, Lopez-Muniz JI, Gil EC, de Juan Ferre A, et al. Defining the optimal sequence for the systemic treatment of
HER2 (including PI3K, mTOR and CDK4/6 inhibitors). Future therapies will be based on molecular profiling and companion diagnostics to allow monitoring and rational selection of targeted treatments for individual patients.

\section{AUTHOR CONTRIBUTIONS}

$\mathrm{AL}$ confirms that he wrote the review by himself in all entirety.

\section{ACKNOWLEDGMENTS}

I am grateful to Elena Perelman, James Whitworth and Jonathan Goddard for reading the manuscript and for valuable feedback and discussion.

metastatic breast cancer. Clin Transl Oncol (2017) 19(2):149-61. doi:10.1007/ s12094-016-1520-2

16. Klapper LN, Waterman H, Sela M, Yarden Y. Tumor-inhibitory antibodies to HER-2/ErbB-2 may act by recruiting c-Cbl and enhancing ubiquitination of HER-2. Cancer Res (2000) 60(13):3384-8.

17. Molina MA, Codony-Servat J, Albanell J, Rojo F, Arribas J, Baselga J. Trastuzumab (herceptin), a humanized anti-Her2 receptor monoclonal antibody, inhibits basal and activated Her2 ectodomain cleavage in breast cancer cells. Cancer Res (2001) 61(12):4744-9.

18. Scaltriti M, Rojo F, Ocana A, Anido J, Guzman M, Cortes J, et al. Expression of p95HER2, a truncated form of the HER2 receptor, and response to antiHER2 therapies in breast cancer. J Natl Cancer Inst (2007) 99(8):628-38. doi:10.1093/jnci/djk134

19. Molina MA, Saez R, Ramsey EE, Garcia-Barchino MJ, Rojo F, Evans AJ, et al. $\mathrm{NH}(2)$-terminal truncated HER-2 protein but not full-length receptor is associated with nodal metastasis in human breast cancer. Clin Cancer Res (2002) 8(2):347-53.

20. Nagata Y, Lan KH, Zhou X, Tan M, Esteva FJ, Sahin AA, et al. PTEN activation contributes to tumor inhibition by trastuzumab, and loss of PTEN predicts trastuzumab resistance in patients. Cancer Cell (2004) 6(2):117-27. doi:10.1016/j.ccr.2004.06.022

21. Seidman AD, Berry D, Cirrincione C, Harris L, Muss H, Marcom PK, et al. Randomized phase III trial of weekly compared with every-3-weeks paclitaxel for metastatic breast cancer, with trastuzumab for all HER-2 overexpressors and random assignment to trastuzumab or not in HER-2 nonoverexpressors: final results of cancer and leukemia group B protocol 9840. J Clin Oncol (2008) 26(10):1642-9. doi:10.1200/JCO.2007.11.6699

22. Clynes RA, Towers TL, Presta LG, Ravetch JV. Inhibitory Fc receptors modulate in vivo cytotoxicity against tumor targets. Nat Med (2000) 6(4):443-6. doi:10.1038/74704

23. Musolino A, Naldi N, Bortesi B, Pezzuolo D, Capelletti M, Missale G, et al. Immunoglobulin $\mathrm{G}$ fragment $\mathrm{C}$ receptor polymorphisms and clinical efficacy of trastuzumab-based therapy in patients with HER-2/neu-positive metastatic breast cancer. J Clin Oncol (2008) 26(11):1789-96. doi:10.1200/ JCO.2007.14.8957

24. Park S, Jiang Z, Mortenson ED, Deng L, Radkevich-Brown O, Yang X, et al. The therapeutic effect of anti-HER2/neu antibody depends on both innate and adaptive immunity. Cancer Cell (2010) 18(2):160-70. doi:10.1016/j. ccr.2010.06.014

25. Rugo HS, Barve A, Waller CF, Hernandez-Bronchud M, Herson J, Yuan J, et al. Effect of a proposed trastuzumab biosimilar compared with trastuzumab on overall response rate in patients with ERBB2 (HER2)-positive metastatic breast cancer: a randomized clinical trial. JAMA (2017) 317(1):37-47. doi:10.1001/jama.2016.18305

26. Jackisch C, Muller V, Dall P, Neumeister R, Park-Simon TW, RufDordelmann A, et al. Subcutaneous trastuzumab for HER2-positive breast cancer - evidence and practical experience in 7 German centers. Geburtshilfe Frauenheilkd (2015) 75(6):566-73. doi:10.1055/s-0035-1546172 
27. Smith MB, Reardon J, Olson EM. Pertuzumab for the treatment of patients with previously untreated HER2-positive metastatic breast cancer. Drugs Today (Barc) (2012) 48(11):713-22. doi:10.1358/dot.2012.48.11. 1885879

28. Nahta R, Hung MC, Esteva FJ. The HER-2-targeting antibodies trastuzumab and pertuzumab synergistically inhibit the survival of breast cancer cells. Cancer Res (2004) 64(7):2343-6. doi:10.1158/0008-5472.CAN-03-3856

29. Baselga J, Gelmon KA, Verma S, Wardley A, Conte P, Miles D, et al. Phase II trial of pertuzumab and trastuzumab in patients with human epidermal growth factor receptor 2-positive metastatic breast cancer that progressed during prior trastuzumab therapy. JClin Oncol (2010) 28(7):1138-44. doi:10.1200/JCO.2009.24.2024

30. Harbeck N, Gnant M. Breast cancer. Lancet (2017) 389(10074):1134-50. doi:10.1016/S0140-6736(16)31891-8

31. Cortes J, Fumoleau P, Bianchi GV, Petrella TM, Gelmon K, Pivot X, et al. Pertuzumab monotherapy after trastuzumab-based treatment and subsequent reintroduction of trastuzumab: activity and tolerability in patients with advanced human epidermal growth factor receptor 2-positive breast cancer. J Clin Oncol (2012) 30(14):1594-600. doi:10.1200/JCO.2011.37.4207

32. Swain SM, Baselga J, Kim SB, Ro J, Semiglazov V, Campone M, et al. Pertuzumab, trastuzumab, and docetaxel in HER2-positive metastatic breast cancer. N Engl J Med (2015) 372(8):724-34. doi:10.1056/NEJMoa1413513

33. Guan Z, Xu B, DeSilvio ML, Shen Z, Arpornwirat W, Tong Z, et al. Randomized trial of lapatinib versus placebo added to paclitaxel in the treatment of human epidermal growth factor receptor 2-overexpressing metastatic breast cancer. J Clin Oncol (2013) 31(16):1947-53. doi:10.1200/JCO.2011.40.5241

34. Cameron D, Casey M, Press M, Lindquist D, Pienkowski T, Romieu CG, et al. A phase III randomized comparison of lapatinib plus capecitabine versus capecitabine alone in women with advanced breast cancer that has progressed on trastuzumab: updated efficacy and biomarker analyses. Breast Cancer Res Treat (2008) 112(3):533-43. doi:10.1007/s10549-007-9885-0

35. Gelmon KA, Boyle FM, Kaufman B, Huntsman DG, Manikhas A, Di Leo A, et al. Lapatinib or trastuzumab plus taxane therapy for human epidermal growth factor receptor 2-positive advanced breast cancer: final results of NCIC CTG MA.31. JClin Oncol (2015) 33(14):1574-83. doi:10.1200/ JCO.2014.56.9590

36. Blackwell KL, Burstein HJ, Storniolo AM, Rugo HS, Sledge G, Aktan G, et al. Overall survival benefit with lapatinib in combination with trastuzumab for patients with human epidermal growth factor receptor 2-positive metastatic breast cancer: final results from the EGF104900 Study. J Clin Oncol (2012) 30(21):2585-92. doi:10.1200/JCO.2011.35.6725

37. Gradishar WJ, Hegg R, Im S, Park I, Tjulandin S, Kenny S, et al. Phase III study of lapatinib (L) plus trastuzumab (T) and aromatase inhibitor (AI) vs $\mathrm{T}+\mathrm{AI}$ vs $\mathrm{L}+\mathrm{AI}$ in postmenopausal women (PMW) with HER2+, HR+ metastatic breast cancer (MBC): ALTERNATIVE. J Clin Oncol (2017) 35(Suppl):abstr1004.

38. Pivot X, Manikhas A, Zurawski B, Chmielowska E, Karaszewska B, Allerton R, et al. CEREBEL (EGF111438): a phase III, randomized, open-label study of lapatinib Plus capecitabine versus trastuzumab plus capecitabine in patients with human epidermal growth factor receptor 2-positive metastatic breast cancer. J Clin Oncol (2015) 33(14):1564-73. doi:10.1200/JCO.2014.57.1794

39. Lambert JM, Morris CQ. Antibody-drug conjugates (ADCs) for personalized treatment of solid tumors: a review. Adv Ther (2017) 34(5):1015-35. doi:10.1007/s12325-017-0519-6

40. Lambert JM, Chari RV. Ado-trastuzumab emtansine (T-DM1): an antibody-drug conjugate (ADC) for HER2-positive breast cancer. J Med Chem (2014) 57(16):6949-64. doi:10.1021/jm500766w

41. Blum RH, Wittenberg BK, Canellos GP, Mayer RJ, Skarin AT, Henderson IC, et al. A therapeutic trial of maytansine. Cancer Clin Trials (1978) 1(2):113-7.

42. Perez EA, Barrios C, Eiermann W, Toi M, Im YH, Conte P, et al. Trastuzumab emtansine with or without pertuzumab versus trastuzumab plus taxane for human epidermal growth factor receptor 2-positive, advanced breast cancer: primary results from the phase III MARIANNE study. J Clin Oncol (2017) 35(2):141-8. doi:10.1200/JCO.2016.67.4887

43. Verma S, Miles D, Gianni L, Krop IE, Welslau M, Baselga J, et al. Trastuzumab emtansine for HER2-positive advanced breast cancer. N Engl J Med (2012) 367(19):1783-91. doi:10.1056/NEJMoa1209124

44. Krop IE, Kim SB, Gonzalez-Martin A, LoRusso PM, Ferrero JM, Smitt $\mathrm{M}$, et al. Trastuzumab emtansine versus treatment of physician's choice for pretreated HER2-positive advanced breast cancer (TH3RESA): a randomised, open-label, phase 3 trial. Lancet Oncol (2014) 15(7):689-99. doi:10.1016/S1470-2045(14)70178-0

45. Krop IE, Kim SB, Martin AG, LoRusso PM, Ferrero JM, BadovinacCrnjevic T, et al. Trastuzumab emtansine versus treatment of physician's choice in patients with previously treated HER2-positive metastatic breast cancer (TH3RESA): final overall survival results from a randomised open-label phase 3 trial. Lancet Oncol (2017) 18(6):743-54. doi:10.1016/ S1470-2045(17)30313-3

46. Dieras V, Miles D, Verma S, Pegram M, Welslau M, Baselga J, et al. Trastuzumab emtansine versus capecitabine plus lapatinib in patients with previously treated HER2-positive advanced breast cancer (EMILIA): a descriptive analysis of final overall survival results from a randomised, open-label, phase 3 trial. Lancet Oncol (2017) 18(6):732-42. doi:10.1016/ S1470-2045(17)30312-1

47. Krop IE, Modi S, LoRusso PM, Pegram M, Guardino E, Althaus B, et al. Phase $1 \mathrm{~b} / 2 \mathrm{a}$ study of trastuzumab emtansine (T-DM1), paclitaxel, and pertuzumab in HER2-positive metastatic breast cancer. Breast Cancer Res (2016) 18(1):34. doi:10.1186/s13058-016-0691-7

48. Vogel CL, Cobleigh MA, Tripathy D, Gutheil JC, Harris LN, Fehrenbacher $\mathrm{L}$, et al. Efficacy and safety of trastuzumab as a single agent in first-line treatment of HER2-overexpressing metastatic breast cancer. J Clin Oncol (2002) 20(3):719-26. doi:10.1200/JCO.2002.20.3.719

49. Hamberg P, Bos MM, Braun HJ, Stouthard JM, van Deijk GA, Erdkamp FL, et al. Randomized phase II study comparing efficacy and safety of combination-therapy trastuzumab and docetaxel vs. sequential therapy of trastuzumab followed by docetaxel alone at progression as firstline chemotherapy in patients with HER2+ metastatic breast cancer: HERTAX trial. Clin Breast Cancer (2011) 11(2):103-13. doi:10.1016/j. clbc.2011.03.003

50. Inoue K, Nakagami K, Mizutani M, Hozumi Y, Fujiwara Y, Masuda N, et al. Randomized phase III trial of trastuzumab monotherapy followed by trastuzumab plus docetaxel versus trastuzumab plus docetaxel as first-line therapy in patients with HER2-positive metastatic breast cancer: the JO17360 trial group. Breast Cancer Res Treat (2010) 119(1):127-36. doi:10.1007/ s10549-009-0498-7

51. Pegram M, Hsu S, Lewis G, Pietras R, Beryt M, Sliwkowski M, et al. Inhibitory effects of combinations of HER-2/neu antibody and chemotherapeutic agents used for treatment of human breast cancers. Oncogene (1999) 18(13):2241-51. doi:10.1038/sj.onc. 1202526

52. Boone JJ, Bhosle J, Tilby MJ, Hartley JA, Hochhauser D. Involvement of the HER2 pathway in repair of DNA damage produced by chemotherapeutic agents. Mol Cancer Ther (2009) 8(11):3015-23. doi:10.1158/1535-7163. MCT-09-0219

53. Bailey TA, Luan H, Clubb RJ, Naramura M, Band V, Raja SM, et al. Mechanisms of trastuzumab resistance in ErbB2-driven breast cancer and newer opportunities to overcome therapy resistance. J Carcinog (2011) 10:28. doi:10.4103/1477-3163.90442

54. Xia W, Bisi J, Strum J, Liu L, Carrick K, Graham KM, et al. Regulation of survivin by ErbB2 signaling: therapeutic implications for ErbB2-overexpressing breast cancers. Cancer Res (2006) 66(3):1640-7. doi:10.1158/0008-5472. CAN-05-2000

55. Lu J, Tan M, Huang WC, Li P, Guo H, Tseng LM, et al. Mitotic deregulation by survivin in ErbB2-overexpressing breast cancer cells contributes to Taxol resistance. Clin Cancer Res (2009) 15(4):1326-34. doi:10.1158/1078-0432. CCR-08-0954

56. Giodini A, Kallio MJ, Wall NR, Gorbsky GJ, Tognin S, Marchisio PC, et al. Regulation of microtubule stability and mitotic progression by survivin. Cancer Res (2002) 62(9):2462-7.

57. Seidman A, Hudis C, Pierri MK, Shak S, Paton V, Ashby M, et al. Cardiac dysfunction in the trastuzumab clinical trials experience. J Clin Oncol (2002) 20(5):1215-21. doi:10.1200/JCO.2002.20.5.1215

58. Bullock K, Blackwell K. Clinical efficacy of taxane-trastuzumab combination regimens for HER-2-positive metastatic breast cancer. Oncologist (2008) 13(5):515-25. doi:10.1634/theoncologist.2007-0204

59. Andersson M, Lidbrink E, Bjerre K, Wist E, Enevoldsen K, Jensen AB, et al. Phase III randomized study comparing docetaxel plus trastuzumab with vinorelbine plus trastuzumab as first-line therapy of metastatic or locally advanced human epidermal growth factor receptor 2-positive breast 
cancer: the HERNATA study. J Clin Oncol (2011) 29(3):264-71. doi:10.1200/ JCO.2010.30.8213

60. Perez EA, Lopez-Vega JM, Petit T, Zamagni C, Easton V, Kamber J, et al. Safety and efficacy of vinorelbine in combination with pertuzumab and trastuzumab for first-line treatment of patients with HER2-positive locally advanced or metastatic breast cancer: VELVET Cohort 1 final results. Breast Cancer Res (2016) 18(1):126. doi:10.1186/s13058-016-0773-6

61. Wardley AM, Pivot X, Morales-Vasquez F, Zetina LM, de Fatima Dias Gaui $\mathrm{M}$, Reyes DO, et al. Randomized phase II trial of first-line trastuzumab plus docetaxel and capecitabine compared with trastuzumab plus docetaxel in HER2-positive metastatic breast cancer. J Clin Oncol (2010) 28(6):976-83. doi:10.1200/JCO.2008.21.6531

62. Valero V, Forbes J, Pegram MD, Pienkowski T, Eiermann W, von Minckwitz G, et al. Multicenter phase III randomized trial comparing docetaxel and trastuzumab with docetaxel, carboplatin, and trastuzumab as first-line chemotherapy for patients with HER2-gene-amplified metastatic breast cancer (BCIRG 007 study): two highly active therapeutic regimens. J Clin Oncol (2011) 29(2):149-56. doi:10.1200/JCO.2010.28.6450

63. von Minckwitz G, du Bois A, Schmidt M, Maass N, Cufer T, de Jongh FE, et al. Trastuzumab beyond progression in human epidermal growth factor receptor 2-positive advanced breast cancer: a German breast group 26/breast international group 03-05 study. J Clin Oncol (2009) 27(12):1999-2006. doi:10.1200/JCO.2008.19.6618

64. Geyer CE, Forster J, Lindquist D, Chan S, Romieu CG, Pienkowski T, et al. Lapatinib plus capecitabine for HER2-positive advanced breast cancer. N Engl J Med (2006) 355(26):2733-43. doi:10.1056/NEJMoa064320

65. Bartsch R, Wenzel C, Altorjai G, Pluschnig U, Rudas M, Mader RM, et al. Capecitabine and trastuzumab in heavily pretreated metastatic breast cancer. J Clin Oncol (2007) 25(25):3853-8. doi:10.1200/JCO.2007.11.9776

66. Howlader N, Altekruse SF, Li CI, Chen VW, Clarke CA, Ries LA, et al. US incidence of breast cancer subtypes defined by joint hormone receptor and HER2 status. J Natl Cancer Inst (2014) 106(5):dju055. doi:10.1093/jnci/ dju055

67. Vici P, Pizzuti L, Sperduti I, Frassoldati A, Natoli C, Gamucci T, et al. “Triple positive" early breast cancer: an observational multicenter retrospective analysis of outcome. Oncotarget (2016) 7(14):17932-44. doi:10.18632/ oncotarget.7480

68. Wu VS, Kanaya N, Lo C, Mortimer J, Chen S. From bench to bedside: what do we know about hormone receptor-positive and human epidermal growth factor receptor 2-positive breast cancer? J Steroid Biochem Mol Biol (2015) 153:45-53. doi:10.1016/j.jsbmb.2015.05.005

69. Giordano SH, Temin S, Kirshner JJ, Chandarlapaty S, Crews JR, Davidson $\mathrm{NE}$, et al. Systemic therapy for patients with advanced human epidermal growth factor receptor 2-positive breast cancer: American society of clinical oncology clinical practice guideline. J Clin Oncol (2014) 32(19):2078-99. doi:10.1200/JCO.2013.54.0948

70. Kaufman B, Mackey JR, Clemens MR, Bapsy PP, Vaid A, Wardley A, et al. Trastuzumab plus anastrozole versus anastrozole alone for the treatment of postmenopausal women with human epidermal growth factor receptor 2-positive, hormone receptor-positive metastatic breast cancer: results from the randomized phase III TAnDEM study. J Clin Oncol (2009) 27(33):552937. doi:10.1200/JCO.2008.20.6847

71. Johnston S, Pippen J Jr, Pivot X, Lichinitser M, Sadeghi S, Dieras V, et al. Lapatinib combined with letrozole versus letrozole and placebo as first-line therapy for postmenopausal hormone receptor-positive metastatic breast cancer. J Clin Oncol (2009) 27(33):5538-46. doi:10.1200/JCO.2009.23.3734

72. Hayashi N, Niikura N, Yamauchi H, Nakamura S, Ueno NT. Adding hormonal therapy to chemotherapy and trastuzumab improves prognosis in patients with hormone receptor-positive and human epidermal growth factor receptor 2-positive primary breast cancer. Breast Cancer Res Treat (2013) 137(2):523-31. doi:10.1007/s10549-012-2336-6

73. Robertson JFR, Bondarenko IM, Trishkina E, Dvorkin M, Panasci L, Manikhas A, et al. Fulvestrant $500 \mathrm{mg}$ versus anastrozole $1 \mathrm{mg}$ for hormone receptor-positive advanced breast cancer (FALCON): an international, randomised, double-blind, phase 3 trial. Lancet (2016) 388(10063):2997-3005. doi:10.1016/S0140-6736(16)32389-3

74. Finn RS, Dering J, Conklin D, Kalous O, Cohen DJ, Desai AJ, et al. PD 0332991, a selective cyclin D kinase 4/6 inhibitor, preferentially inhibits proliferation of luminal estrogen receptor-positive human breast cancer cell lines in vitro. Breast Cancer Res (2009) 11(5):R77. doi:10.1186/bcr2419

75. Hortobagyi GN, Stemmer SM, Burris HA, Yap YS, Sonke GS, PaluchShimon S, et al. Ribociclib as first-line therapy for HR-positive, advanced breast cancer. N Engl J Med (2016) 375(18):1738-48. doi:10.1056/NEJMoa 1609709

76. Loibl S, Turner NC, Ro J, Cristofanilli M, Iwata H, Im SA, et al. Palbociclib combined with fulvestrant in premenopausal women with advanced breast cancer and prior progression on endocrine therapy: PALOMA-3 results. Oncologist (2017) 22(9):1028-38. doi:10.1634/theoncologist.2017-0072

77. Cardoso F, Costa A, Senkus E, Aapro M, Andre F, Barrios CH, et al. 3rd ESO-ESMO international consensus guidelines for advanced breast cancer (ABC 3). Ann Oncol (2017) 28(1):16-33. doi:10.1093/annonc/mdw544

78. Urruticoechea A, Rizwanullah M, Im SA, Ruiz ACS, Lang I, Tomasello G, et al. Randomized phase III trial of trastuzumab plus capecitabine with or without pertuzumab in patients with human epidermal growth factor receptor 2-positive metastatic breast cancer who experienced disease progression during or after trastuzumab-based therapy. JClin Oncol (2017) 35(26):3030-8. doi:10.1200/JCO.2016.70.6267

79. Cameron D, Casey M, Oliva C, Newstat B, Imwalle B, Geyer CE. Lapatinib plus capecitabine in women with HER-2-positive advanced breast cancer: final survival analysis of a phase III randomized trial. Oncologist (2010) 15(9):924-34. doi:10.1634/theoncologist.2009-0181

80. Blackwell KL, Burstein HJ, Storniolo AM, Rugo H, Sledge G, Koehler M, et al. Randomized study of Lapatinib alone or in combination with trastuzumab in women with ErbB2-positive, trastuzumab-refractory metastatic breast cancer. J Clin Oncol (2010) 28(7):1124-30. doi:10.1200/JCO.2008.21.4437

81. von Minckwitz G, Schwedler K, Schmidt M, Barinoff J, Mundhenke C, Cufer T, et al. Trastuzumab beyond progression: overall survival analysis of the GBG 26/BIG 3-05 phase III study in HER2-positive breast cancer. Eur J Cancer (2011) 47(15):2273-81. doi:10.1016/j.ejca.2011.06.021

82. De Mattos-Arruda L, Cortes J. Advances in first-line treatment for patients with HER-2+ metastatic breast cancer. Oncologist (2012) 17(5):631-44. doi:10.1634/theoncologist.2011-0187

83. Gavila J, Lopez-Tarruella S, Saura C, Munoz M, Oliveira M, De la CruzMerino L, et al. SEOM clinical guidelines in metastatic breast cancer 2015. Clin Transl Oncol (2015) 17(12):946-55. doi:10.1007/s12094-015$1476-7$

84. Martinez-Janez N, Chacon I, de Juan A, Cruz-Merino L, Del Barco S, Fernandez I, et al. Anti-HER2 therapy beyond second-line for HER2-positive metastatic breast cancer: a short review and recommendations for several clinical scenarios from a Spanish expert panel. Breast Care (Basel) (2016) 11(2):133-8. doi:10.1159/000443601

85. Liedtke C, Thill M, Hanf V, Schuutz F; Committee AGOB. AGO recommendations for the diagnosis and treatment of patients with advanced and metastatic breast cancer: update 2015. Breast Care (Basel) (2015) 10(3):199-205. doi:10.1159/000431248

86. Prat A, Baselga J. The role of hormonal therapy in the management of hormonal-receptor-positive breast cancer with co-expression of HER2. Nat Clin Pract Oncol (2008) 5(9):531-42. doi:10.1038/ncponc1179

87. Lousberg L, Collignon J, Jerusalem G. Resistance to therapy in estrogen receptor positive and human epidermal growth factor 2 positive breast cancers: progress with latest therapeutic strategies. Ther Adv Med Oncol (2016) 8(6):429-49. doi:10.1177/1758834016665077

88. Collins D, Jacob W, Cejalvo JM, Ceppi M, James I, Hasmann M, et al. Direct estrogen receptor (ER)/HER family crosstalk mediating sensitivity to lumretuzumab and pertuzumab in ER+ breast cancer. PLoS One (2017) 12(5):e0177331. doi:10.1371/journal.pone.0177331

89. Wang YC, Morrison G, Gillihan R, Guo J, Ward RM, Fu X, et al. Different mechanisms for resistance to trastuzumab versus lapatinib in HER2-positive breast cancers - role of estrogen receptor and HER2 reactivation. Breast Cancer Res (2011) 13(6):R121. doi:10.1186/bcr3067

90. Giuliano M, Hu H, Wang YC, Fu X, Nardone A, Herrera S, et al. Upregulation of ER signaling as an adaptive mechanism of cell survival in HER2-positive breast tumors treated with anti-HER2 therapy. Clin Cancer Res (2015) 21(17):3995-4003. doi:10.1158/1078-0432.CCR-14-2728

91. Giuliano M, Trivedi MV, Schiff R. Bidirectional crosstalk between the estrogen receptor and human epidermal growth factor receptor 2 signaling 
pathways in breast cancer: molecular basis and clinical implications. Breast Care (Basel) (2013) 8(4):256-62. doi:10.1159/000354253

92. Schwartzberg LS, Franco SX, Florance A, O’Rourke L, Maltzman J, Johnston S. Lapatinib plus letrozole as first-line therapy for HER-2+ hormone receptor-positive metastatic breast cancer. Oncologist (2010) 15(2):122-9. doi:10.1634/theoncologist.2009-0240

93. Huober J, Fasching PA, Barsoum M, Petruzelka L, Wallwiener D, Thomssen C, et al. Higher efficacy of letrozole in combination with trastuzumab compared to letrozole monotherapy as first-line treatment in patients with HER2-positive, hormone-receptor-positive metastatic breast cancer - results of the eLEcTRA trial. Breast (2012) 21(1):27-33. doi:10.1016/j.breast.2011. 07.006

94. Early Breast Cancer Trialists' Collaborative Group (EBCTCG). Effects of chemotherapy and hormonal therapy for early breast cancer on recurrence and 15-year survival: an overview of the randomised trials. Lancet (2005) 365(9472):1687-717. doi:10.1016/S0140-6736(05)66544-0

95. Berry DA, Cirrincione C, Henderson IC, Citron ML, Budman DR, Goldstein LJ, et al. Estrogen-receptor status and outcomes of modern chemotherapy for patients with node-positive breast cancer. JAMA (2006) 295(14):1658-67. doi:10.1001/jama.295.14.1658

96. Arpino G, Ferrero J-M, Haba-Rodriguez J, Easton V, Schuhmacher C, Restuccia E, et al. Primary analysis of PERTAIN: a randomized, two-arm, open-label, multicenter phase II trial assessing the efficacy and safety of pertuzumab given in combination with trastuzumab plus an aromatase inhibitor in first-line patients with HER2-positive and hormone receptor-positive metastatic or locally advanced breast cancer. Cancer Res (2017) 77(4 Suppl):Abstract nr S3-04. doi:10.1158/1538-7445.SABCS16-S3-04 (Proceedings of the 2016 San Antonio Breast Cancer Symposium)

97. Finn RS, Martin M, Rugo HS, Jones S, Im SA, Gelmon K, et al. Palbociclib and letrozole in advanced breast cancer. N Engl J Med (2016) 375(20):1925-36. doi:10.1056/NEJMoa1607303

98. Jeselsohn R, De Angelis C, Brown M, Schiff R. The evolving role of the estrogen receptor mutations in endocrine therapy-resistant breast cancer. Curr Oncol Rep (2017) 19(5):35. doi:10.1007/s11912-017-0591-8

99. Gong Y, Liu YR, Ji P, Hu X, Shao ZM. Impact of molecular subtypes on metastatic breast cancer patients: a SEER population-based study. Sci Rep (2017) 7:45411. doi:10.1038/srep45411

100. Leone JP, Leone BA. Breast cancer brain metastases: the last frontier. Exp Hematol Oncol (2015) 4:33. doi:10.1186/s40164-015-0028-8

101. Bartmann C, Wischnewsky M, Stuber T, Stein R, Krockenberger M, Hausler $\mathrm{S}$, et al. Pattern of metastatic spread and subcategories of breast cancer. Arch Gynecol Obstet (2017) 295(1):211-23. doi:10.1007/s00404-016-4225-4

102. Aversa C, Rossi V, Geuna E, Martinello R, Milani A, Redana S, et al. Metastatic breast cancer subtypes and central nervous system metastases. Breast (2014) 23(5):623-8. doi:10.1016/j.breast.2014.06.009

103. Yuan P, Gao SL. Management of breast cancer brain metastases: focus on human epidermal growth factor receptor 2-positive breast cancer. Chronic Dis Transl Med (2017) 3(1):21-32. doi:10.1016/j.cdtm.2017.01.004

104. Ramakrishna N, Temin S, Chandarlapaty S, Crews JR, Davidson NE, Esteva $\mathrm{FJ}$, et al. Recommendations on disease management for patients with advanced human epidermal growth factor receptor 2-positive breast cancer and brain metastases: American society of clinical oncology clinical practice guideline. J Clin Oncol (2014) 32(19):2100-8. doi:10.1200/JCO.2013.54.0955

105. Soffietti R, Abacioglu U, Baumert B, Combs SE, Kinhult S, Kros JM, et al. Diagnosis and treatment of brain metastases from solid tumors: guidelines from the European Association of Neuro-Oncology (EANO). Neuro Oncol (2017) 19(2):162-74. doi:10.1093/neuonc/now241

106. Arslan C, Dizdar O, Altundag K. Systemic treatment in breast-cancer patients with brain metastasis. Expert Opin Pharmacother (2010) 11(7):1089-100. doi:10.1517/14656561003702412

107. Bendell JC, Domchek SM, Burstein HJ, Harris L, Younger J, Kuter I, et al. Central nervous system metastases in women who receive trastuzumab-based therapy for metastatic breast carcinoma. Cancer (2003) 97(12):2972-7. doi:10.1002/cncr.11436

108. Gori S, Rimondini S, De Angelis V, Colozza M, Bisagni G, Moretti G, et al. Central nervous system metastases in HER-2 positive metastatic breast cancer patients treated with trastuzumab: incidence, survival, and risk factors. Oncologist (2007) 12(7):766-73. doi:10.1634/theoncologist.12-7-766
109. Clayton AJ, Danson S, Jolly S, Ryder WD, Burt PA, Stewart AL, et al. Incidence of cerebral metastases in patients treated with trastuzumab for metastatic breast cancer. Br J Cancer (2004) 91(4):639-43. doi:10.1038/sj.bjc.6601970

110. Park YH, Park MJ, Ji SH, Yi SY, Lim DH, Nam DH, et al. Trastuzumab treatment improves brain metastasis outcomes through control and durable prolongation of systemic extracranial disease in HER2-overexpressing breast cancer patients. Br J Cancer (2009) 100(6):894-900. doi:10.1038/ sj.bjc.6604941

111. Rostami R, Mittal S, Rostami P, Tavassoli F, Jabbari B. Brain metastasis in breast cancer: a comprehensive literature review. J Neurooncol (2016) 127(3):407-14. doi:10.1007/s11060-016-2075-3

112. Stemmler HJ, Schmitt M, Willems A, Bernhard H, Harbeck N, Heinemann $\mathrm{V}$. Ratio of trastuzumab levels in serum and cerebrospinal fluid is altered in HER2-positive breast cancer patients with brain metastases and impairment of blood-brain barrier. Anticancer Drugs (2007) 18(1):23-8. doi:10.1097/01. cad.0000236313.50833.ee

113. Morikawa A, Peereboom DM, Thorsheim HR, Samala R, Balyan R, Murphy CG, et al. Capecitabine and lapatinib uptake in surgically resected brain metastases from metastatic breast cancer patients: a prospective study. Neuro Oncol (2015) 17(2):289-95. doi:10.1093/neuonc/noul41

114. Lin NU. Breast cancer brain metastases: new directions in systemic therapy. Ecancermedicalscience (2013) 7:307. doi:10.3332/ecancer.2013.307

115. Bachelot T, Romieu G, Campone M, Dieras V, Cropet C, Dalenc F, et al. Lapatinib plus capecitabine in patients with previously untreated brain metastases from HER2-positive metastatic breast cancer (LANDSCAPE): a single-group phase 2 study. Lancet Oncol (2013) 14(1):64-71. doi:10.1016/ S1470-2045(12)70432-1

116. Krop IE, Lin NU, Blackwell K, Guardino E, Huober J, Lu M, et al. Trastuzumab emtansine (T-DM1) versus lapatinib plus capecitabine in patients with HER2-positive metastatic breast cancer and central nervous system metastases: a retrospective, exploratory analysis in EMILIA. Ann Oncol (2015) 26(1):113-9. doi:10.1093/annonc/mdu486

117. Swain SM, Baselga J, Miles D, Im YH, Quah C, Lee LF, et al. Incidence of central nervous system metastases in patients with HER2-positive metastatic breast cancer treated with pertuzumab, trastuzumab, and docetaxel: results from the randomized phase III study CLEOPATRA. Ann Oncol (2014) 25(6):1116-21. doi:10.1093/annonc/mdu133

118. Chan A. Neratinib in HER-2-positive breast cancer: results to date and clinical usefulness. Ther Adv Med Oncol (2016) 8(5):339-50. doi:10.1177/1758834016656494

119. Papademetriou IT, Porter T. Promising approaches to circumvent the bloodbrain barrier: progress, pitfalls and clinical prospects in brain cancer. Ther Deliv (2015) 6(8):989-1016. doi:10.4155/tde.15.48

120. Rabindran SK. Antitumor activity of HER-2 inhibitors. Cancer Lett (2005) 227(1):9-23. doi:10.1016/j.canlet.2004.11.015

121. Chan A, Delaloge S, Holmes FA, Moy B, Iwata H, Harvey VJ, et al. Neratinib after trastuzumab-based adjuvant therapy in patients with HER2-positive breast cancer (ExteNET): a multicentre, randomised, double-blind, placebo-controlled, phase 3 trial. Lancet Oncol (2016) 17(3):367-77. doi:10.1016/ S1470-2045(15)00551-3

122. Awada A, Colomer R, Inoue K, Bondarenko I, Badwe RA, Demetriou G, et al. Neratinib plus paclitaxel vs trastuzumab plus paclitaxel in previously untreated metastatic ERBB2-positive breast cancer: the NEfERT-T randomized clinical trial. JAMA Oncol (2016) 2(12):1557-64. doi:10.1001/ jamaoncol.2016.0237

123. Martin M, Bonneterre J, Geyer CE Jr, Ito Y, Ro J, Lang I, et al. A phase two randomised trial of neratinib monotherapy versus lapatinib plus capecitabine combination therapy in patients with HER2+ advanced breast cancer. Eur J Cancer (2013) 49(18):3763-72. doi:10.1016/j.ejca.2013.07.142

124. Harbeck N, Huang CS, Hurvitz S, Yeh DC, Shao Z, Im SA, et al. Afatinib plus vinorelbine versus trastuzumab plus vinorelbine in patients with HER2overexpressing metastatic breast cancer who had progressed on one previous trastuzumab treatment (LUX-Breast 1): an open-label, randomised, phase 3 trial. Lancet Oncol (2016) 17(3):357-66. doi:10.1016/S1470-2045(15)00540-9

125. Krop IE. Lessons from breast cancer trials of HER2-kinase inhibitors. Lancet Oncol (2016) 17(3):267-8. doi:10.1016/S1470-2045(16)00004-8

126. Moulder SL, Borges VF, Baetz T, McSpadden T, Fernetich G, Murthy RK, et al. Phase I study of ONT-380, a HER2 inhibitor, in patients with 
HER2+-advanced solid tumors, with an expansion cohort in HER2+ metastatic breast cancer (MBC). Clin Cancer Res (2017) 23(14):3529-36. doi:10.1158/1078-0432.CCR-16-1496

127. Borges VF, Ferrario C, Aucoin N, Falkson CI, Khan QJ, Krop IE, et al. Efficacy results of a phase $1 \mathrm{~b}$ study of ONT-380, a CNS-penetrant TKI, in combination with T-DM1 in HER2+ metastatic breast cancer (MBC), including patients (pts) with brain metastases. J Clin Oncol (2016) 34(15_suppl):513. doi:10.1200/JCO.2016.34.15_suppl.513

128. Baselga J, Campone M, Piccart M, Burris HA III, Rugo HS, Sahmoud T, et al. Everolimus in postmenopausal hormone-receptor-positive advanced breast cancer. N Engl J Med (2012) 366(6):520-9. doi:10.1056/NEJMoa1109653

129. Hurvitz SA, Andre F, Jiang Z, Shao Z, Mano MS, Neciosup SP, et al. Combination of everolimus with trastuzumab plus paclitaxel as firstline treatment for patients with HER2-positive advanced breast cancer (BOLERO-1): a phase 3, randomised, double-blind, multicentre trial. Lancet Oncol (2015) 16(7):816-29. doi:10.1016/S1470-2045(15)00051-0

130. Yardley D, Hurvitz S, Jiang Z-F, Toi M, Burris H, Buyse M, et al. Everolimus plus trastuzumab and paclitaxel as first-line therapy in women with HER2+ advanced breast cancer: overall survival results from BOLERO-1. Cancer Res (2017) 77(4 Suppl). doi:10.1158/1538-7445.SABCS16-P4-22-13 (Proceedings of the 2016 San Antonio Breast Cancer Symposium; 2016 Dec 6-10; San Antonio, TX. Philadelphia (PA): AACR):Abstract nr P4-22-13

131. Andre F, O'Regan R, Ozguroglu M, Toi M, Xu B, Jerusalem G, et al. Everolimus for women with trastuzumab-resistant, HER2-positive, advanced breast cancer (BOLERO-3): a randomised, double-blind, placebo-controlled phase 3 trial. Lancet Oncol (2014) 15(6):580-91. doi:10.1016/S1470-2045(14) 70138-X

132. Isaacs C, O’Regan R, Xu B, Masuda N, Aren AF, Yap Y-S, et al. Everolimus plus trastuzumab and vinorelbine for trastuzumab-resistant, taxane-pretreated, HER2+ advanced breast cancer: overall survival results from BOLERO-3. Cancer Res (2016) 76(4 Suppl). doi:10.1158/1538-7445.SABCS15-P4-13-12 (Proceedings of the Thirty-Eighth Annual CTRC-AACR San Antonio Breast Cancer Symposium: 2015 Dec 8-12):Abstract nr P4-13-2

133. Andre F, Hurvitz S, Fasolo A, Tseng LM, Jerusalem G, Wilks S, et al. Molecular alterations and everolimus efficacy in human epidermal growth factor receptor 2-overexpressing metastatic breast cancers: combined exploratory biomarker analysis from BOLERO-1 and BOLERO-3. J Clin Oncol (2016) 34(18):2115-24. doi:10.1200/JCO.2015.63.9161

134. Sirohi B, Rastogi S, Dawood S. Buparlisib in breast cancer. Future Oncol (2015) 11(10):1463-70. doi:10.2217/fon.15.56

135. Jain S, Nye L, Santa-Maria C, Bontemps L, Williams A, Garrett H, et al. Phase I study of alpelisib and T-DM1 in trastuzumab-refractory HER2-positive metastatic breast cancer. Cancer Res (2015) 76(4 Suppl). doi:10.1158/15387445.SABCS15-P6-13-11 (Proceedings of the Thirty-Eighth Annual CTRC-AACR San Antonio Breast Cancer Symposium: 2015 Dec 8-12; San Antonio):Abstract nr P6-13-1

136. Bertoli C, Skotheim JM, de Bruin RA. Control of cell cycle transcription during G1 and S phases. Nat Rev Mol Cell Biol (2013) 14(8):518-28. doi: $10.1038 / \mathrm{nrm} 3629$

137. Ormandy CJ, Musgrove EA, Hui R, Daly RJ, Sutherland RL. Cyclin D1, EMS1 and $11 \mathrm{q} 13$ amplification in breast cancer. Breast Cancer Res Treat (2003) 78(3):323-35. doi:10.1023/A:1023033708204

138. Yu Q, Geng Y, Sicinski P. Specific protection against breast cancers by cyclin D1 ablation. Nature (2001) 411(6841):1017-21. doi:10.1038/35082500

139. Casimiro MC, Wang C, Li Z, Di Sante G, Willmart NE, Addya S, et al. Cyclin D1 determines estrogen signaling in the mammary gland in vivo. Mol Endocrinol (2013) 27(9):1415-28. doi:10.1210/me.2013-1065

140. Sledge GW Jr, Toi M, Neven P, Sohn J, Inoue K, Pivot X, et al. MONARCH 2: abemaciclib in combination with fulvestrant in women with $\mathrm{HR}+$ / HER2- advanced breast cancer who had progressed while receiving endocrine therapy. J Clin Oncol (2017) 35(25):2875-84. doi:10.1200/JCO.2017. 73.7585

141. Turner NC, Ro J, Andre F, Loi S, Verma S, Iwata H, et al. Palbociclib in hormone-receptor-positive advanced breast cancer. N Engl J Med (2015) 373(3):209-19. doi:10.1056/NEJMoa1505270

142. Venur VA, Leone JP. Targeted therapies for brain metastases from breast cancer. Int J Mol Sci (2016) 17(9):1543. doi:10.3390/ijms17091543
143. Witkiewicz AK, Cox D, Knudsen ES. CDK4/6 inhibition provides a potent adjunct to Her2-targeted therapies in preclinical breast cancer models. Genes Cancer (2014) 5(7-8):261-72. doi:10.18632/genesandcancer.24

144. Corona SP, Ravelli A, Cretella D, Cappelletti MR, Zanotti L, Dester M, et al. CDK4/6 inhibitors in HER2-positive breast cancer. Crit Rev Oncol Hematol (2017) 112:208-14. doi:10.1016/j.critrevonc.2017.02.022

145. Rasola A. HSP90 proteins in the scenario of tumor complexity. Oncotarget (2017) 8(13):20521-2. doi:10.18632/oncotarget.16266

146. Chandarlapaty S, Scaltriti M, Angelini P, Ye Q, Guzman M, Hudis CA, et al. Inhibitors of HSP90 block p95-HER2 signaling in trastuzumab-resistant tumors and suppress their growth. Oncogene (2010) 29(3):325-34. doi:10.1038/onc.2009.337

147. Friedland JC, Smith DL, Sang J, Acquaviva J, He S, Zhang C, et al. Targeted inhibition of Hsp90 by ganetespib is effective across a broad spectrum of breast cancer subtypes. Invest New Drugs (2014) 32(1):14-24. doi:10.1007/ s10637-013-9971-6

148. Modi S, Stopeck A, Linden H, Solit D, Chandarlapaty S, Rosen N, et al. HSP90 inhibition is effective in breast cancer: a phase II trial of tanespimycin (17AAG) plus trastuzumab in patients with HER2-positive metastatic breast cancer progressing on trastuzumab. Clin Cancer Res (2011) 17(15):5132-9. doi:10.1158/1078-0432.CCR-11-0072

149. Modi S, Saura C, Henderson C, Lin NU, Mahtani R, Goddard J, et al. A multicenter trial evaluating retaspimycin HCL (IPI-504) plus trastuzumab in patients with advanced or metastatic HER2-positive breast cancer. Breast Cancer Res Treat (2013) 139(1):107-13. doi:10.1007/s10549-013-2510-5

150. Li W, Tsen F, Sahu D, Bhatia A, Chen M, Multhoff G, et al. Extracellular Hsp90 (eHsp90) as the actual target in clinical trials: intentionally or unintentionally. Int Rev Cell Mol Biol (2013) 303:203-35. doi:10.1016/ B978-0-12-407697-6.00005-2

151. Jhaveri K, Ochiana SO, Dunphy MP, Gerecitano JF, Corben AD, Peter RI, et al. Heat shock protein 90 inhibitors in the treatment of cancer: current status and future directions. Expert Opin Investig Drugs (2014) 23(5):611-28. doi:10.1517/13543784.2014.902442

152. Carmeliet P, Jain RK. Angiogenesis in cancer and other diseases. Nature (2000) 407(6801):249-57. doi:10.1038/35025220

153. Loureiro RM, Maharaj AS, Dankort D, Muller WJ, D’Amore PA. ErbB2 overexpression in mammary cells upregulates VEGF through the core promoter. Biochem Biophys Res Commun (2005) 326(2):455-65. doi:10.1016/j. bbrc.2004.11.053

154. Konecny GE, Meng YG, Untch M, Wang HJ, Bauerfeind I, Epstein M, et al. Association between HER-2/neu and vascular endothelial growth factor expression predicts clinical outcome in primary breast cancer patients. Clin Cancer Res (2004) 10(5):1706-16. doi:10.1158/1078-0432.CCR-0951-3

155. Zhao M, Pan X, Layman R, Lustberg MB, Mrozek E, Macrae ER, et al. A phase II study of bevacizumab in combination with trastuzumab and docetaxel in HER2 positive metastatic breast cancer. Invest New Drugs (2014) 32(6):1285-94. doi:10.1007/s10637-014-0122-5

156. Gianni L, Romieu GH, Lichinitser M, Serrano SV, Mansutti M, Pivot X, et al. AVEREL: a randomized phase III Trial evaluating bevacizumab in combination with docetaxel and trastuzumab as first-line therapy for HER2positive locally recurrent/metastatic breast cancer. JClin Oncol (2013) 31(14):1719-25. doi:10.1200/JCO.2012.44.7912

157. Slamon DJ. Primary results from BETH, a phase 3 controlled study of adjuvant chemotherapy and trastuzumab \pm bevacizumab in patients with HER2-positive, node-positive or high risk node-negative breast cancer. Cancer Res (2013) 73(24 Suppl). doi:10.1158/0008-5472.SABCS13-S1-03 Abstract nr S1-03,

158. Fakhrejahani E, Toi M. Antiangiogenesis therapy for breast cancer: an update and perspectives from clinical trials. Jpn J Clin Oncol (2014) 44(3):197-207. doi:10.1093/jico/hyt201

159. Manso L, Moreno F, Marquez R, Castelo B, Arcediano A, Arroyo M, et al. Use of bevacizumab as a first-line treatment for metastatic breast cancer. Curr Oncol (2015) 22(2):e51-60. doi:10.3747/co.22.2210

160. Agatsuma T. Development of new ADC technology with topoisomerase I inhibitor. Yakugaku Zasshi (2017) 137(5):545-50. doi:10.1248/ yakushi.16-00255-4

161. Tamura K, Shitara K, Naito Y, Shimomura A, Fujiwara Y, Yonemori K, et al. Single agent activity of DS-8201a, a HER2-targeting antibody-drug 
conjugate, in breast cancer patients previously treated with T-DM1: phase 1 dose escalation. Ann Oncol (2016) 27(Suppl_6):LBA17. doi:10.1093/annonc/ mdw435.07

162. Bergstrom DA, Bodyak N, Yurkovetskiy A, Park PU, DeVit M, Yin M, et al. A novel, highly potent HER2-targeted antibody-drug conjugate (ADC) for the treatment of low HER2-expressing tumors and combination with trastuzumab based regimens in HER2-driven tumors. Cancer Res (2015) 75(15 Suppl): abstract LBA-231. doi:10.1158/1538-7445.AM2015-LB-231 (Proceedings of the 106th Annual Meeting of the American Association for Cancer Research; 2015 Apr 18-22; Philadelphia)

163. Miller K, Cortes J, Hurvitz SA, Krop IE, Tripathy D, Verma S, et al. HERMIONE: a randomized Phase 2 trial of MM-302 plus trastuzumab versus chemotherapy of physician's choice plus trastuzumab in patients with previously treated, anthracycline-naive, HER2-positive, locally advanced/metastatic breast cancer. BMC Cancer (2016) 16:352. doi:10.1186/ s12885-016-2385-z

164. Pallerla S, Gauthier T, Sable R, Jois SD. Design of a doxorubicin-peptidomimetic conjugate that targets HER2-positive cancer cells. Eur J Med Chem (2017) 125:914-24. doi:10.1016/j.ejmech.2016.10.015

165. Kang X, Guo X, An W, Niu X, Li S, Liu Z, et al. Photothermal therapeutic application of gold nanorods-porphyrin-trastuzumab complexes in HER2positive breast cancer. Sci Rep (2017) 7:42069. doi:10.1038/srep42069

166. Bang YJ, Giaccone G, Im SA, Oh DY, Bauer TM, Nordstrom JL, et al. Firstin-human phase 1 study of margetuximab (MGAH22), an Fc-modified chimeric monoclonal antibody, in patients with HER2-positive advanced solid tumors. Ann Oncol (2017) 28(4):855-61. doi:10.1093/annonc/mdx002

167. Rugo HS, Pegram MD, Gradishar WJ, Cortes J, Curigliano G, Hong S, et al. SOPHIA: a phase 3, randomized study of margetuximab plus chemotherapy vs trastuzumab plus chemotherapy in the treatment of patients with HER2+ metastatic breast cancer. Cancer Res (2017) 77(4 Suppl). doi:10.1158/15387445.SABCS16-OT1-02-07 (Proceedings of the 2016 San Antonio Breast Cancer Symposium; 2016 Dec 6-10; San Antonio):Abstract nr OT1-02-7
168. Haense N, Atmaca A, Pauligk C, Steinmetz K, Marme F, Haag GM, et al. A phase I trial of the trifunctional anti Her2 $\mathrm{x}$ anti CD3 antibody ertumaxomab in patients with advanced solid tumors. BMC Cancer (2016) 16:420. doi:10.1186/s12885-016-2449-0

169. Kiewe P, Hasmuller S, Kahlert S, Heinrigs M, Rack B, Marme A, et al. Phase I trial of the trifunctional anti-HER2 $\mathrm{x}$ anti-CD3 antibody ertumaxomab in metastatic breast cancer. Clin Cancer Res (2006) 12(10):3085-91. doi:10.1158/1078-0432.CCR-05-2436

170. Disis ML, Dang Y, Coveler AL, Marzbani E, Kou ZC, Childs JS, et al. HER-2/neu vaccine-primed autologous T-cell infusions for the treatment of advanced stage HER-2/neu expressing cancers. Cancer Immunol Immunother (2014) 63(2):101-9. doi:10.1007/s00262-013-1489-4

171. Disis ML, Wallace DR, Gooley TA, Dang Y, Slota M, Lu H, et al. Concurrent trastuzumab and HER2/neu-specific vaccination in patients with metastatic breast cancer. J Clin Oncol (2009) 27(28):4685-92. doi:10.1200/ JCO.2008.20.6789

172. Cameron D, Piccart-Gebhart MJ, Gelber RD, Procter M, Goldhirsch A, de Azambuja E, et al. 11 years' follow-up of trastuzumab after adjuvant chemotherapy in HER2-positive early breast cancer: final analysis of the HERceptin adjuvant (HERA) trial. Lancet (2017) 389(10075):1195-205. doi:10.1016/ S0140-6736(16)32616-2

Conflict of Interest Statement: The author declares that the research was conducted in the absence of any commercial or financial relationships that could be construed as a potential conflict of interest.

Copyright (c) 2018 Larionov. This is an open-access article distributed under the terms of the Creative Commons Attribution License (CC BY). The use, distribution or reproduction in other forums is permitted, provided the original author(s) and the copyright owner are credited and that the original publication in this journal is cited, in accordance with accepted academic practice. No use, distribution or reproduction is permitted which does not comply with these terms. 